\title{
Spectroscopic and Computational Studies on the Rearrangement of lonized [1.1.1]Propellane and Some of its Valence Isomers: The Key Role of Vibronic Coupling
}

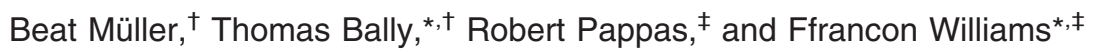 \\ Department of Chemistry, University of Fribourg, Switzerland, and Department of Chemistry, \\ University of Tennessee, Knoxville, Tennessee
}

\begin{abstract}
The [1.1.1]propellane radical cation $\mathbf{1}^{{ }^{++}}$, generated by radiolytic oxidation of the parent compound in argon and Freon matrices at low temperatures, undergoes a spontaneous rearrangement to form the distonic 1,1-dimethyleneallene (or 2-vinylideneallyl) radical cation $3^{{ }^{++}}$consisting of an allyl radical substituted at the 2-position by a vinyl cation. In similar matrix studies, it is found that the isomeric dimethylenecyclo-

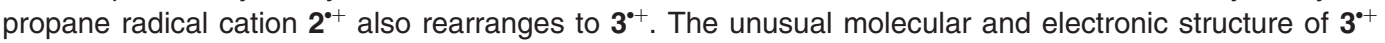
has been established by the results of ESR, UV-vis, and IR spectroscopic measurements in conjunction with detailed theoretical calculations. Also of particular interest is an NIR photoinduced reaction by which $3^{\cdot+}$ is cleanly converted to the vinylidenecyclopropane radical cation $4^{\cdot+}$, a process that can be represented in terms of a single electron transfer from the allyl radical to the vinyl cation followed by allyl cation cyclization. The specificity of this photochemical reaction provides additional strong chemical evidence for the structure of $3^{\circ+}$. Theoretical calculations reveal the decisive role of vibronic coupling in shaping the potential energy

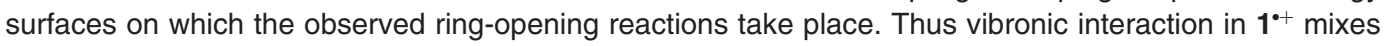

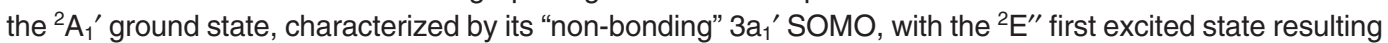
in the destabilization of a lateral $\mathrm{C}-\mathrm{C}$ bond and the initial formation of the methylenebicyclobutyl radical cation $\mathbf{5}^{\mathbf{}}$. The further rearrangement of $\mathbf{5}^{\cdot+}$ to $3^{\mathbf{0}^{+}}$occurs via $\mathbf{2}^{\cdot+}$ and proceeds through two additional latera/ $\mathrm{C}-\mathrm{C}$ bond cleavages characterized by transition states of extremely low energy, thereby explaining the absence of identifiable intermediates along the reaction pathway. In these consecutive ring-opening rearrangements, the "non-bonding" bridgehead $\mathrm{C}-\mathrm{C}$ bond in $\mathbf{1}^{\circ+}$ is conserved and ultimately transformed into a normal bond characterized by a shorter $\mathrm{C}-\mathrm{C}$ bond length. This work provides strong support for the Heilbronner-Wiberg interpretation of the vibrational structure in the photoelectron spectrum of 1 in terms of vibronic coupling.
\end{abstract}

\section{Introduction}

Although tricyclo[1.1.1.0 $\left.0^{1,3}\right]$ pentane (1), usually referred to as [1.1.1]propellane, possesses one of the highest strain energies per $\mathrm{C}-\mathrm{C}$ bond of all known cycloalkanes, ${ }^{1}$ the neutral molecule is in fact remarkably stable to either thermal decomposition or polymerization, and this lack of reactivity underlies its successful preparation., ${ }^{2,3}$ This high thermal stability of $\mathbf{1}$ has been attributed to the clasping effect of the three methylene groups so that the dissociation of the central $\mathrm{C}_{1}-\mathrm{C}_{3}$ bond brings about almost no strain relief. ${ }^{1,4}$ Moreover, due to a big HOMO-LUMO gap, ${ }^{5-9}$ the open-shell singlet and triplet diradical states lie very high

\footnotetext{
$\dagger$ University of Fribourg.
University of Tennessee.

(1) Wiberg, K. B. Angew. Chem., Int. Ed. Engl. 1986, 25, 312.

(2) Wiberg, K. B.; Walker, F. H. J. Am. Chem. Soc. 1982, 104, 5239.

(3) Semmler, K.; Szeimies, G.; Belzner, J. J. Am. Chem. Soc. 1985, 107, 6410.

(4) Wiberg, K. B. Chem. Rev. 1989, 89, 975.

(5) Newton, M. D.; Schulman, J. M. J. Am. Chem. Soc. 1972, 94, 773

(6) Stohrer, W.-D.; Hoffmann, R. J. Am. Chem. Soc. 1972, 94, 779.

(7) Jackson, J. E.; Allen, L. C. J. Am. Chem. Soc. 1984, 106, 591.

(8) Feller, D.; Davidson, E. R. J. Am. Chem. Soc. 1987, 109, 4133.

(9) Wiberg, K. B.; Hadad, C. M.; Sieber, S.; Schleyer, P. v. R. J. Am. Chem. Soc. 1992, 114, 5820.
}

in energy, ${ }^{5}$ so that $\mathbf{1}$ is not substantially stabilized on lengthening the $\mathrm{C}_{1}-\mathrm{C}_{3}$ bond.

In some respects, this central bond in $\mathbf{1}$ corresponds to a normal bond, and thus (a) it is only $6 \%$ longer than the $\mathrm{C}-\mathrm{C}$ bond in cyclopropane,${ }^{10}$ (b) its thermochemical strength has been assessed to be ca. $70 \%$ of that of a conventional $\mathrm{C}-\mathrm{C}$ bond, ${ }^{1,4,8}$ and (c) its stretching force constant is in the expected range. ${ }^{10}$ On the other hand, the analyses of overlap populations ${ }^{5}$ and other wave function-derived characteristics ${ }^{7,8}$ did not reveal an unambigous "electronic basis" that might account for these localized bonding properties, prompting the statement that "no irrefutable case can be made either proving or disproving the existence of a 'bond' between the bridgehead atoms in 1.,"8

Very recently, some of the differing views on the nature of the central bond in $\mathbf{1}$ have been reconciled by identifying it as a "charge-shift" bond, such as that which prevails in molecular fluorine. ${ }^{11}$ However, leaving aside this enigmatic character of the central bond, complete agreement exists that the $3 \mathrm{a}_{1}{ }^{\prime} \mathrm{HOMO}$

(10) Wiberg, K. B.; Dailey, W. P.; Walker, F. H.; Wadell, S. T.; Crocker, L. S.; Newton, M. J. Am. Chem. Soc. 1985, 107, 7247.

(11) Wu, W.; Gu, J.; Song, J.; Shaik, S.; Hiberty, P. C. Angew. Chem., Int. Ed. 2009, 48, 1407. 


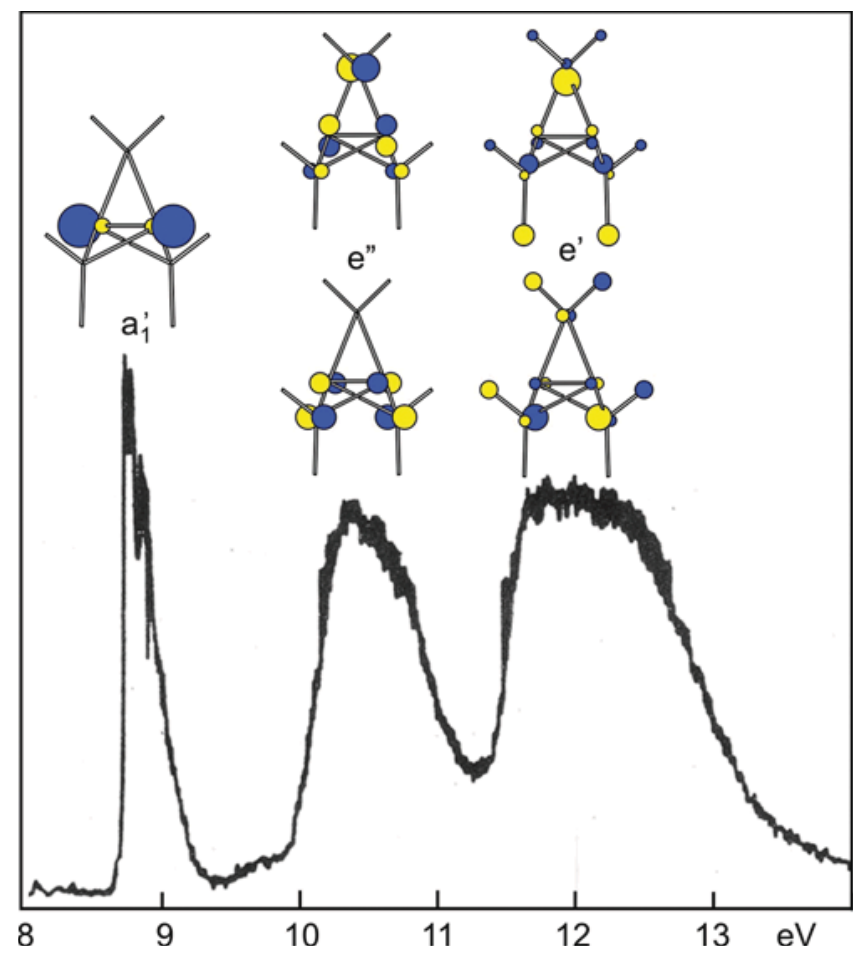

Figure 1. Photoelectron spectrum of [1.1.1]propellane (1), reproduced from ref 13, and pictorial representation of the molecular orbitals from which ionization occurs.

of $\mathbf{1}$ does not contribute appreciably to $\mathrm{C}_{1}-\mathrm{C}_{3}$ bonding. ${ }^{5-8,12}$ This can be ascribed to the "inverted-tetrahedron" geometry that prevails at the bridgehead atoms, ${ }^{12}$ which means that most of the $3 \mathrm{a}_{1}{ }^{\prime}$ orbital's amplitude lies outside the molecule ${ }^{5,7-9}$ so that the HOMO is essentially nonbonding (see MO drawing in Figure 1). Experimental support for this HOMO description comes from the observation of an intense sharp 0,0 vibrational component in the first band of the photoelectron spectrum of $\mathbf{1},{ }^{13}$ implying that the rigid structure of the molecule is retained on ionization with little or no change in geometry.

Similarly, theoretical calculations ${ }^{8}$ predict that the $\mathrm{C}_{1}-\mathrm{C}_{3}$ distance is largely unaffected by ionization, the small decrease from $1.6 \AA$ for $\mathbf{1}$ to $1.55 \AA$ for $\mathbf{1}^{+}$formally suggesting, if anything, a slightly antibonding character to the $3 \mathrm{a}_{1}{ }^{\prime}$ orbital. In view of the above, one would expect that ionization of 1 (i.e., removal of an electron from the HOMO) should lead only to very minor structural changes. This is in contrast to the situation for other strained hydrocarbons with HOMOs that are strongly $\mathrm{C}-\mathrm{C} \sigma$-bonding, such as bicyclo[1.1.0]butane ${ }^{14-17}$ and bicyclo[2.1.0]pentane. ${ }^{14,18,19}$ Indeed, the central bonds of these molecules are found to undergo considerable weakening on ionization, as clearly revealed by the above-cited ESR and theoretical studies.

(12) Wiberg, K. B. Acc. Chem. Res. 1984, 17, 379.

(13) Honegger, E.; Huber, H.; Heilbronner, E.; Dailey, W. P.; Wiberg, K. B. J. Am. Chem. Soc. 1985, 107, 7172.

(14) Gassman, P. G. In Photoinduced Electran Transfer Reactions: Organic Substrates; Fox, M. A., Chanon, M., Eds.; Elsevier: Amsterdam, 1988; p 70.

(15) Newton, M. D.; Schulman, J. M. J. Am. Chem. Soc. 1972, 94, 767.

(16) Gerson, F.; Qin, X.-Z.; Ess, C.; Kloster-Jensen, E. J. Am. Chem. Soc. 1989, 111, 6456.

(17) Bally, T. J. Mol. Struct. 1991, 227, 249.

(18) Williams, F.; Guo, Q.-X.; Kolb, T. M.; Nelsen, S. F. J. Chem. Soc., Chem. Commun. 1989, 1835.

(19) Adam, W.; Walter, H.; Chen, G.-F.; Williams, F. J. Am. Chem. Soc. 1992, 114, 3007.
Scheme 1<smiles></smiles>

Scheme 2

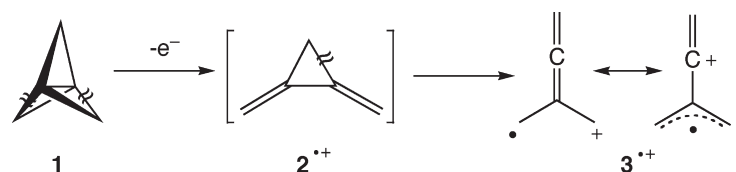

The above expectation that $\mathbf{1}$ should survive one-electron oxidation structurally intact, despite its considerable strain, was tempered, however, by previous studies on oxiranes. ${ }^{20,21}$ In this case, the seemingly contradictory results of photoionization from a nonbonding $\mathrm{p}-\mathrm{AO}$ on the oxygen atom ${ }^{22}$ and $\mathrm{C}-\mathrm{C}$ ring opening by radiolytic oxidation at low temperatures ${ }^{20}$ were observed (Scheme 1), these findings eventually being reconciled theoretically. ${ }^{21,23}$

Our studies of $\mathbf{1}$ now reveal an even more remarkable oxidative rearrangement, one in which eventually three lateral framework bonds of $\mathbf{1}^{\mathbf{+}}$ break, and perhaps even more unexpectedly, a "normal" $\mathrm{C}-\mathrm{C}$ bond is reconstituted between the carbons originally at the bridgehead positions, the final product being the distonic 1,1-dimethyleneallene (or 2-vinylideneallyl) radical cation $3^{\circ+}$ possessing both substituted vinyl cation and allyl radical moieties. The same product is obtained on ionization of dimethylenecyclopropane $\mathbf{2}$, so the corresponding radical cation is probably an intermediate in the decay of $\mathbf{1}^{\cdot+}$ (Scheme 2).

The key to understanding this unprecedented rearrangement is provided by theoretical calculations that reveal the decisive role of vibronic coupling ${ }^{24,25}$ in shaping the potential energy landscape on which the observed reaction takes place. Essentially, vibronic interaction mixes the ${ }^{2} \mathrm{~A}^{\prime}$ ground state, characterized by its nonbonding $3 \mathrm{a}_{1}{ }^{\prime} \mathrm{SOMO}$, with the ${ }^{2} \mathrm{E}^{\prime \prime}$ first excited state, a process that results in a weakening of the lateral $\mathrm{C}-\mathrm{C}$ bonds. The possible importance of this vibronic coupling was actually first suggested by Heilbronner, Wiberg, and their co-workers ${ }^{13}$ in discussing the low-frequency $\left(360 \pm 20 \mathrm{~cm}^{-1}\right)$ vibrational progression that they discerned in the first band in the photoelectron spectrum of $\mathbf{1}$. They argued that this progression could not be assigned to any of the allowed totally symmetric modes that may be stimulated on electron ejection from the $3 \mathrm{a}_{1}{ }^{\prime}$ orbital of $\mathbf{1}$ because these would all be expected to have much higher frequencies. Instead, the authors proposed that one explanation for the low-frequency mode could reside in the aforementioned vibronic coupling of the ground state with the proximate degenerate excited state. ${ }^{13}$ As a result of our present studies which originate from a totally different direction,

(20) Snow, L. D.; Wang, J. T.; Williams, F. Chem. Phys. Lett. 1983, 100, 193.

(21) Williams, F. Radiat. Phys. Chem. 2003, 67, 211.

(22) McAlduff, E. J.; Houk, K. N. Can. J. Chem. 1977, 55, 318.

(23) Nobes, R. H.; Bouma, W. J.; McLeod, L.; Radom, L. Chem. Phys. Lett. 1987, 135, 78.

(24) Bersuker, I. B. The Jahn-Teller Effect; Cambridge University Press: Cambridge, U.K., 2006.

(25) Köppel, H.; Domcke, W.; Cederbaum, L. S.; Shaik, S. S. Angew. Chem., Int. Ed. 1983, 22, 210. 
this earlier conjecture on the significance of vibronic coupling in $\mathbf{1}^{\mathbf{}+}$ is revealed to be well substantiated.

\section{Experimental Section}

Syntheses of Compounds 1, 2, and 4. [1.1.1]Propellane, 1, was made by adding methyllithium to a solution of 1,1,-dibromo-2,2bis(chloromethyl)cyclopropane in cold diethyl ether according to the procedure of Belzner et al. ${ }^{26}$ As $\mathbf{1}$ is difficult to separate from the solvent, it was reacted with $\mathrm{I}_{2}$ and thus converted to 1,3diiodobicyclopentane, ${ }^{27}$ a stable, crystalline compound that can be reconverted as needed to $\mathbf{1}$ by reducing it with sodium cyanide in DMSO, from which it can be separated by fractional condensation under vacuum. ${ }^{27}$ Compound $\mathbf{1}$ is trapped as a white, powdery solid at $77 \mathrm{~K}$ and can be stored at $-78{ }^{\circ} \mathrm{C}$ for weeks in the absence of air without appreciable decomposition. ${ }^{1} \mathrm{H}$ NMR $\left(\mathrm{CDCl}_{3}\right): \delta 2.65$ $(\mathrm{s}, 6 \mathrm{H})$.

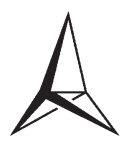

1

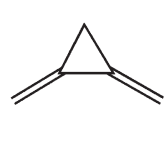

2

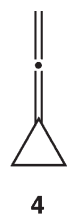

Above $350{ }^{\circ} \mathrm{C}$ in the gas phase, $\mathbf{1}$ decomposes to dimethylenecyclopropane, 2, and vinylidenecyclopropane, 4, which are in thermal equilibrium under these conditions. ${ }^{28}$ Thus, the latter two compounds can in principle be obtained by flash vacuum pyrolysis of $\mathbf{1}$. However, we decided to use a higher yield "wet" synthesis of $\mathbf{4}$ that is based on a procedure published by the group of Conia for the preparation of bicyclopropylidene. ${ }^{29}$

Thus, dibromocarbene was added to methylenecyclopropane ${ }^{30}$ (which was made from methallyl chloride and potassium amide ${ }^{31}$ ) to yield 2,2-dibromospiropentane, which upon dehalogenation with methyllithium undergoes ring opening to give $\mathbf{4}$ in $25 \%$ isolated yield (based on methylenecyclopropane). Samples of $\mathbf{4}$ used for matrix isolation were further purified by preparative $\mathrm{GC}$ on $35 \%$ ODP/Chromosorb at $35{ }^{\circ} \mathrm{C} .{ }^{1} \mathrm{H}$ NMR $\left(\mathrm{CDCl}_{3}\right): \delta 1.52(\mathrm{t}, 4 \mathrm{H}), 4.81$ (q, 2H).

Dimethylenecyclopropane, 2 . This compound was obtained by flash vacuum pyrolysis of $4(0.1 \mathrm{mbar})$ through an empty $40 \mathrm{~cm}$ quartz tube $\left(10 \mathrm{~mm}\right.$ i.d.) at $500{ }^{\circ} \mathrm{C}$ (where 2 predominates in the thermal equilibrium). ${ }^{28}$ The crude reaction mixture was separated by preparative GC (same conditions as for 4). ${ }^{1} \mathrm{H} \mathrm{NMR}\left(\mathrm{CDCl}_{3}\right)$ : $\delta 1.58(\mathrm{~m}, 2 \mathrm{H}), 5.31(\mathrm{~m}, 2 \mathrm{H}), 5.54(\mathrm{~m}, 2 \mathrm{H})$. Unreacted 4 was recovered for further pyrolysis.

Matrix Isolation Spectroscopy. For the generation of radical cations in Freon solutions, the hydrocarbons were dissolved to a concentration of ca. $5 \times 10^{-3} \mathrm{M}$ in different Freons: $\mathrm{CFCl}_{3}(\mathrm{~F}-11)$, $\mathrm{CF}_{2} \mathrm{ClCCl}_{3}$ (F-112a), and $\mathrm{CF}_{3} \mathrm{CCl}_{3}$ (F-113a) for ESR spectroscopy, and a $1: 1$ mixture of $\mathrm{CFCl}_{3}$ and $\mathrm{CF}_{2} \mathrm{BrCF}_{2} \mathrm{Br}$, which forms a transparent glass, for optical spectroscopy. ${ }^{32}$ After freezing to 77 $\mathrm{K}$, the solutions were exposed to ca. $0.5 \mathrm{Mrad}$ of $\gamma$-irradiation from a ${ }^{60} \mathrm{Co}$ source. To obtain well resolved ESR spectra, the resulting samples were warmed to $90-110 \mathrm{~K}$.

For the purpose of Ar matrix isolation, the neutral precursor molecules were mixed in a $2 \mathrm{~L}$ glass bulb in a ratio of 1:1000 with a 9:1 mixture of $\mathrm{Ar}$ and $\mathrm{N}_{2}$ (which serves to improve the optical quality of matrices) to which an equimolar part of $\mathrm{CH}_{2} \mathrm{Cl}_{2}$ was added to act as an electron scavenger. Approximately 80 Torr of

(26) Belzner, J.; Bunz, U.; Semmler, K.; Szeimies, G.; Opitz, K.; Schlüter, A.-D. Chem. Ber. 1989, 122, 397.

(27) Alber, F.; Szeimies, G. Chem. Ber. 1992, 125, 757.

(28) Bloch, R.; Le Perchec, P.; Conia, J. M. Angew. Chem., Int. Ed. 1970, 9, 798.

(29) Le Perchec, P.; Conia, J. M. Tetrahedron Lett. 1970, 19, 1587.

(30) Lukin, K. A.; Zefirov, N. S. Zh. Org. Khim. 1987, 23, 2548.

(31) Köster, R.; Arora, S.; Binger, P. Angew. Chem., Int. Ed. 1969, 8.

(32) Grimison, A.; Simpson, G. A. J. Phys. Chem. 1968, 72, 1776. the above gas mixture was sprayed over the course of $1 \mathrm{~h}$ onto a CsI window, held at $20 \mathrm{~K}$ in a closed-cycle cryostat, where the gases condensed to form a transparent matrix. After cooling to 10 $\mathrm{K}$, the matrix was exposed to $\mathrm{X}$-irradiation (bremsstrahlung from a tungsten target exposed to a $40 \mathrm{~mA}$ current of $40 \mathrm{kV}$ ). The electron-hole pairs generated by that process in Ar are trapped by the added dopants (for the electron capture we use $\mathrm{CH}_{2} \mathrm{Cl}_{2}$ ). Ionization of the hydrocarbon substrate then occurs by hole transfer from $\mathrm{Ar}^{+},{ }^{33}$ a processs that is exothermic by several $\mathrm{eV}$. The excess energy imparted onto the incipient hydrocarbon radical cations, which cannot be easily dissipated in solid Ar, may induce rearrangements that are not observed upon radiolytic oxidation in Freon glasses. This is often the reason for differences observed in the optical spectra observed in Freon and Ar matrices.

Wavelength-selective photolyses were brought about by irradiation with medium or high-pressure $\mathrm{Hg} / \mathrm{Xe}$ or $\mathrm{Ar}$ resonance lamps through appropriate cutoff or bandpass filters. For electronic absorption spectroscopy, a Perkin-Elmer Lambda 900 instrument was employed, and IR spectra were recorded on a Bomem DA3 interferometer using a liquid nitrogen cooled midrange MCT detector.

ESR Experiments. Solutions containing $0.005-0.01 \mathrm{M}$ concentrations of $\mathbf{1}, \mathbf{2}$, and $\mathbf{4}$ in Freon solvents $\left(\mathrm{CFCl}_{3}, \mathrm{CF}_{3} \mathrm{CCl}_{3}\right.$, $\mathrm{CF}_{2} \mathrm{ClCFCl}_{2}$ ) were prepared on a vacuum line in Spectrosil ESR sample tubes ( $3 \mathrm{~mm}$ i.d.) and $\gamma$-irradiated at $77 \mathrm{~K}$ for a typical radiation dose of $0.2 \operatorname{Mrad}\left(1 \mathrm{Mrad}=10 \mathrm{kGy}=1 \times 10^{4} \mathrm{~J} \mathrm{~kg}^{-1}\right)$. Additional details of sample preparation and reasons for the recommended concentration range are described elsewhere. ${ }^{19,34}$ After irradiation, the sample tube was quickly transferred from liquid nitrogen into a variable-temperature Dewar insert mounted inside the cavity of an ESR spectrometer (Bruker ER 200D SRC), the initial temperature being ca. $80 \mathrm{~K}$. The X-band microwave frequency was recorded with a Systron-Donner 6054 B counter, and the magnetic fields were determined by an NMR gaussmeter (Bruker ER $035 \mathrm{M}$ ). Spectra were recorded at intervals of 5-10 K on progressive annealing, the observed spectral changes being monitored for reversibility by recycling to the lower temperature.

Photoelectron Spectra. The photoelectron (PE) spectrum of $\mathbf{1}$ was reproduced from the literature. ${ }^{13}$ That of $\mathbf{2}$ was measured on a modified Perkin-Elmer PE 16 instrument operated in preretardation (and hence constant resolution) mode. ${ }^{35}$

Quantum Chemical Calculations. The geometries of all species were optimized by the B3LYP/6-31G* method, which has proven very reliable in predicting radical cation geometries. ${ }^{36}$ Force fields calculated by the same method were used to model IR spectra (after scaling of all frequencies by a suitable factor) and the thermochemical corrections to the relative energies (see below). Fermi contact terms to predict ESR hyperfine coupling constants were also taken from B3LYP/6-31G* calculations. Derivative coupling vectors between the ground and the first excited state of radical cations (see Further Rearrangements in Results and Discussion) were calculated by doing one cycle of a $(4,4) \mathrm{CASSCF} / 6-31 \mathrm{G} *$ conical intersection calculation. All of the above calculations were done using the Gaussian 98 and 03 suite of programs. ${ }^{37}$

Absolute energies were calculated at the RCCSD(T)/cc-pVTZ level, using the Molpro program, ${ }^{38}$ to which zero-point vibrational energies (ZPVE) from the above-described DFT calculations were added. The relative energies shown and discussed in this paper are ZPVE corrected RCCSD(T) energies. Cartesian coordinates, ab-

(33) Bally, T. In Radical Ionic Systems; Lund, A., Shiotani, M., Eds.; Kluwer: Dordrecht, 1991; p 3.

(34) Qin, X.-Z.; Snow, L. D.; Williams, F. J. Am. Chem. Soc. 1985, 107, 3366.

(35) Dressler, R.; Neuhaus, L.; Allan, M. J. Electron Spectrosc. Relat. Phenom. 1983, 31, 181.

(36) Bally, T. Rev. Comput. Chem. 1999, 13, 1.

(37) Frisch, M. J. et al. Gaussian 98 and Gaussian 03 (different revisions); Gaussin, Inc.: Wallingford, CT, 2003.

(38) Werner, H.-J.; Knowles, P. J. MOLPRO, version 2002.6; University College Cardiff Consultants Ltd.: Cardiff, 2004. 


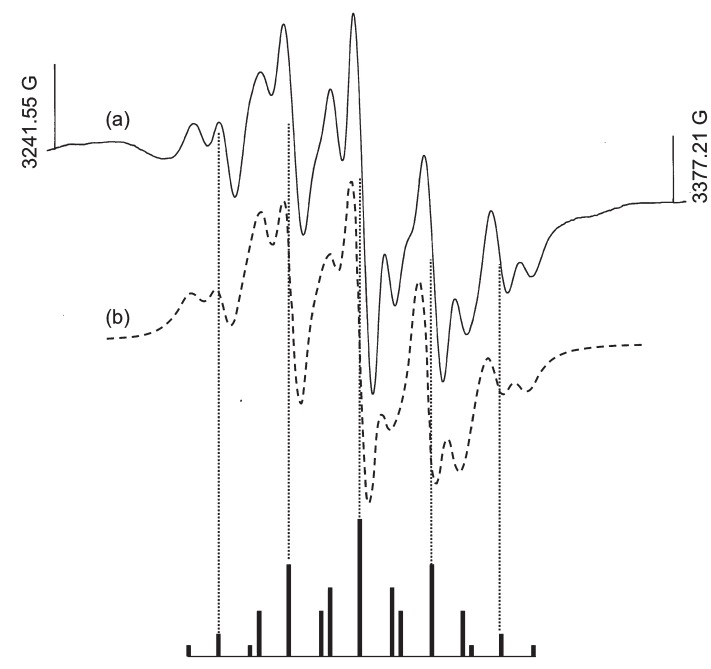

Figure 2. (a) ESR spectrum obtained at $110 \mathrm{~K}$ after radiolytic oxidation of 1 in $\mathrm{CF}_{3} \mathrm{CCl}_{3}$ at $77 \mathrm{~K}$. (b) Simulation of the spectrum based on the assignment given at the bottom.

solute energies, and thermal corrections for all stationary points evaluated in this work are listed in the Supporting Information.

Electronic absorption spectra were modeled by the CASSCF/ CASPT2 method ${ }^{39}$ using the ANO-S basis set and the Molcas suite of progams. ${ }^{40}$ The choice of active spaces is indicated in the tables where results are listed. To avoid problems with intruder states in the CASPT2 calculations, a series of calculations with level shifts varying from 0.05 to $0.25 \mathrm{~h}$ were carried out, always ascertaining that the relative energies of states that are not affected by intruders do not change significantly.

To ascertain whether multideterminantal effects may prohibit the $\operatorname{CCSD}(\mathrm{T})$ method from yielding reliable predictions of relative energies, all stationary points were recalculated by CASSCF using the ANO-S basis set and an active space of 11 electrons in 10 orbitals. However, the ground states are invariably described to almost $90 \%$ by a single configuration, and no excited configuration contributes more than $4 \%$. Relative CASPT2 energies obtained on this basis were found to be in reasonable accord with the results from CCSD(T)(cc-pVTZ calculations (see Figure S7 in Supporting Information).

Molecular orbitals were plotted using the MOPlot program. ${ }^{41}$

\section{Results and Discussion}

Ionization of 1 and 2. Figure 2 shows the ESR spectrum recorded at $110 \mathrm{~K}$ after the radiolytic oxidation of $\mathbf{1}$ in a $\mathrm{CF}_{3} \mathrm{CCl}_{3}$ matrix at $77 \mathrm{~K}$. The well-resolved hyperfine pattern is readily analyzed as a $1: 4: 6: 4: 1$ quintet $(a(4 \mathrm{H})=14.8 \mathrm{G})$ of $1: 2: 1$ triplets $(a(2 \mathrm{H})=5.4 \mathrm{G})$, and this analysis is confirmed by the spectral simulation shown in Figure 2. Clearly, the form of the ESR spectrum rules out the possibility that the carrier of this signal is the unrearranged radical cation $\mathbf{1}^{\mathbf{}}$, which would be expected to give rise to a septet pattern from six equivalent hydrogens. The spectra obtained in other chlorofluorocarbon matrices show the same distinct quintet pattern, although the triplet substructure is not as well resolved in $\mathrm{CFCl}_{3}$ and $\mathrm{CF}_{2} \mathrm{ClCCl}_{3}$ at temperatures

(39) Andersson, K.; Roos, B. O. In Modern Electronic Structure Theory World Scientific Publishing Co.: Singapore, 1995.

40) Lindh, R.; Malmqvist, P.-A.; Roos, B. O.; Ryde, U.; Veryazov, V.; Widmark, P.-O.; Cossi, M.; Schimmelpfennig, B.; Neogrady, P.; Seijo, L. Comput. Mater. Sci. 2003, 28, 222.

(41) Olkhov, R. V.; Matzinger, S.; Bally, T. MoPlot (Molecular Orbital Plotting program) Version 1.85 for Windows, Linux and Mac OS X; University of Fribourg: Switzerland; see http://www-chem-unifr.ch/ tb/moplot/moplot.html.

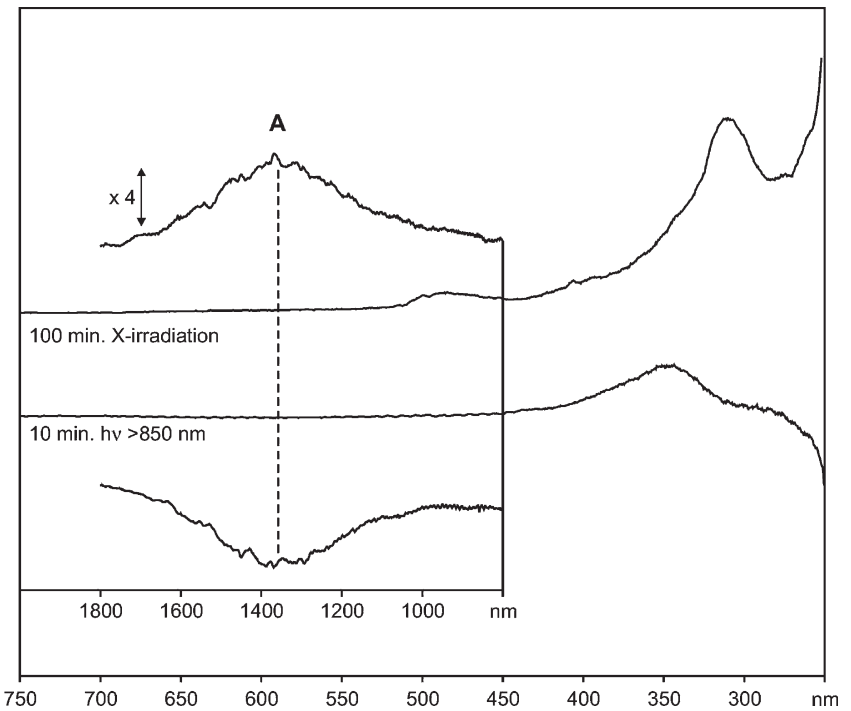

Figure 3. Difference spectrum for X-irradiation of $\mathbf{1}$ and for subsequent NIR photolysis. The band labeled A belongs to the photobleachable species that is created upon ionization of $\mathbf{1}$.

below $100 \mathrm{~K}$ and is broadened considerably in $\mathrm{CF}_{2} \mathrm{ClCFCl}_{2}$ at $90 \mathrm{~K}$. Confirmation that the primary species formed by radiolysis of $\mathbf{1}$ in these Freon matrices are identical is provided by the observation that the signal carrier, although unaffected by exposure to visible light, is sensitive in all cases to photolysis by near-IR light above $800 \mathrm{~nm}$ (vide infra).

Ionization of 1 in $\mathrm{CFCl}_{3} / \mathrm{CF}_{2} \mathrm{BrCF}_{2} \mathrm{Br}$, a Freon mixture that forms a transparent glass, results in a rather nondescript EA spectrum that increases gradually toward the UV. However, ionization by $\mathrm{X}$-irradiation in $\mathrm{Ar}$ gave a spectrum with three distinct bands: a very weak structured one in the NIR $\left(\lambda_{\max } \cong\right.$ $1400 \mathrm{~nm}$ ), a second weak one around $480 \mathrm{~nm}$, and an intense one at $310 \mathrm{~nm}$, in addition to a few small peaks between the second and the third band (see Figure 3). Irradiation through a $850 \mathrm{~nm}$ cutoff filter led to the complete bleaching of the NIR band, whereas the other spectroscopic features remained unaffected, except for a small increase around $350 \mathrm{~nm}$ and the onset of a decrease below $270 \mathrm{~nm}$.

Clearly the band at $1400 \mathrm{~nm}$ cannot belong to $\mathbf{1}^{++}$because (a) the gap betweeen the first $\left({ }^{2} \mathrm{~A}_{1}{ }^{\prime}\right)$ and the second band $\left({ }^{2} \mathrm{E}^{\prime \prime}\right)$ in the PE spectrum in Figure 1 amounts to $>1.5 \mathrm{eV}$ and (b) ${ }^{2} \mathrm{~A}_{1}{ }^{\prime} \rightarrow{ }^{2} \mathrm{E}^{\prime \prime}$ transitions are electric dipole forbidden in $\mathrm{D}_{3 h}$ symmetry. The transition to the ${ }^{2} \mathrm{E}^{\prime}$ state, ca. $3 \mathrm{eV}$ above the ${ }^{2} \mathrm{~A}_{1}{ }^{\prime}$ ground state, would be allowed, but that region of the spectrum (around $400 \mathrm{~nm}$ ) is devoid of absorptions. The bands peaking at ca. 500 and at $310 \mathrm{~nm}$ seem to belong to the same species, because they can be bleached by prolonged $>475 \mathrm{~nm}$ photolysis, whereby the characteristic bands of the radical cation of cyclopentadiene are observed to arise. Such pairs of bands are typical for conjugated diene radical cations. ${ }^{42}$

The same sequence of ionization and subsequent NIR photolysis, this time monitored in the mid-IR range, is illustrated in Figure 4 where three sections of the IR difference spectra are shown. These spectra show the rise of a set of peaks on ionization, at least 12 of which disappear again on subsequent NIR photobleaching, as indicated by the vertical dashed lines connecting the peaks labeled $\mathbf{A}$ in Figure 4. Group theory

(42) Shida, T. Electronic Absorption Spectra of Organic Radical Ions; Elsevier: Amsterdam, 1988. 

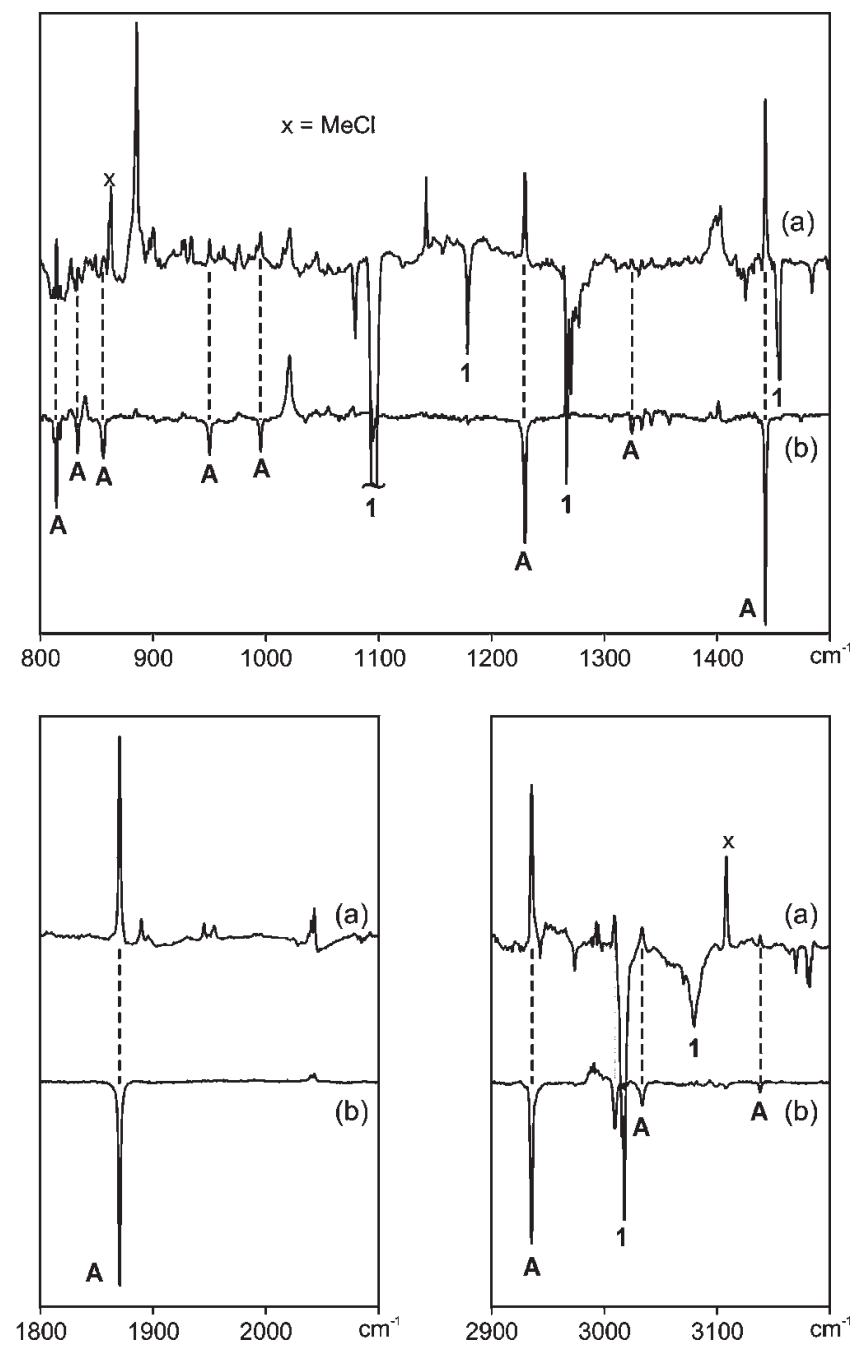

Figure 4. IR difference spectra for (a) the ionization of $\mathbf{1}$ by X-irradation in $\mathrm{Ar}$ and (b) subsequent bleaching by photolysis at $>850 \mathrm{~nm}$. The bands labeled $\mathbf{A}$ belong to the photobleachable species that is formed on ionization of $\mathbf{1}$.

indicates that $\mathbf{1}$ has only $6 \mathrm{e}^{\prime}$ and $2 \mathrm{a}_{2}^{\prime \prime}$ vibrations that are IRactive, of which two are $\mathrm{C}-\mathrm{H}$ stretches. Clearly more IR bands are associated with the species that arises on ionization of $\mathbf{1}$ in $\mathrm{Ar}$ and its subsequent bleaching, which indicates that this species must have lower symmetry than $\mathrm{D}_{3 h}$, in accord with the conclusions based on the ESR spectrum. Interestingly, the most intense peak in the IR spectrum of this species is at $1870 \mathrm{~cm}^{-1}$, a region where molecules containing cumulated double bonds typically show strong absorptions.

However, it should be pointed out that more IR peaks arise on ionization of $\mathbf{1}$ in Ar than are bleached by NIR photolysis, some of which occur also in the region of $1900-2100 \mathrm{~cm}^{-1}$. These bands may be associated with the bands at 500 and 310 $\mathrm{nm}$ in the UV-vis spectrum shown in Figure 3, a proposition that will be examined later.

The conclusions from the above experiments are that ionization of $\mathbf{1}$ in Freon or Ar matrices leads to a photosensitive species with a set of four and a set of two equivalent hydrogens. The sole electronic absorption that is discernible for this species above $260 \mathrm{~nm}$ is a weak, structured band peaking at ca. 1400 $\mathrm{nm}$ that can be bleached by NIR irradiation. This photolysis leads also to the disappearance of a set of at least 12 IR bands that are formed (next to others) on ionization in Ar.

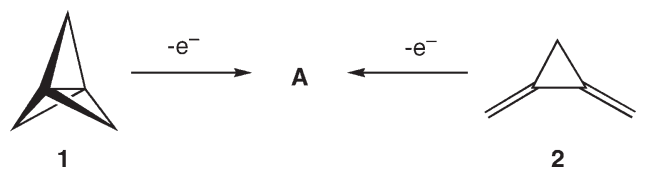

Thus, it seems, in contrast to the expectations based on the nature of the ground state of $\mathbf{1}^{\mathbf{+}}$ (see Introduction), this cation does not preserve its structural integrity but undergoes some spontaneous relaxation to a species of lower symmetry. In the following sections we will elucidate the nature of and the reasons for this spontaneous decay of a cation that would at first sight have no reason to depart significantly from the geometry of its neutral precursor, $\mathbf{1}$.

Remarkably, similar experiments conducted on the oxidation of 2 gave ESR and optical spectra that were nearly identical with those derived from $\mathbf{1}$, when compared under the same conditions of matrix and temperature (see Figure S1 of the Supporting Information). The IR spectrum after ionization differed more (see Figure S2 in the Supporting Information), but all of the peaks of species $\mathbf{A}$ were clearly visible, and the difference spectrum for bleaching of that species was again almost identical to that shown in Figure $4 \mathrm{~b}$.

Thus, both $\mathbf{1}$ and $\mathbf{2}$ appear to yield a common radical cation intermediate $\mathbf{A}$ despite the fact that the two parent molecules have very different structures (Scheme 3 ). This is clearly indicative of a rather extensive rearrangement of the parent molecules upon ionization leading almost certainly to the formation of a very stable intermediate corresponding to the signal carrier A. Of course, it is not possible to conclude from these results that the transformation of $\mathbf{1}^{\mathbf{}}$ proceeds directly through the radical cation of $\mathbf{2}$ to this intermediate, although this is a possible scenario given that $\mathbf{2}$ formally contains two fewer cyclopropane rings than $\mathbf{1}$. This issue of the reaction pathway will be addressed theoretically in detail later in this paper.

Assignment of Photosensitive Radical Cation Obtained on Ionization of 1 or 2 . The first significant clue as to the unusual structure of the signal carrier $\mathbf{A}$ came from thermal annealing studies in $\mathrm{CF}_{2} \mathrm{ClCFCl}_{2}$ where ion-molecule reactions are wellknown to occur above $100 \mathrm{~K}$, leading to the formation of neutral radicals as a result of proton or hydrogen-atom transfer. ${ }^{43,44}$ As shown in Figure 5, the broadened five-line ESR pattern from the primary species at $90 \mathrm{~K}$ (which corresponds to a poorly resolved version of the spectrum in Figure 2) decays at $115 \mathrm{~K}$ to give a quintet of very sharp lines with a similar splitting constant of $14.6 \mathrm{G}$.

The spectrum at $115 \mathrm{~K}$ is unaffected by near-IR bleaching, which shows that the spectral change observed on annealing does not result from improved resolution, but that $\mathbf{A}$ had irreversibly transformed into a secondary radical B. Most revealing is the magnitude of the $4 \mathrm{H}$-coupling $(14.7 \pm 0.1 \mathrm{G})$ in both $\mathbf{A}$ and $\mathbf{B}$. This is reminiscent of the $14.4 \mathrm{G}$ splitting observed for the spectra of neutral allyl radicals obtained from olefins in Freon matrices, ${ }^{43,44}$ where the small difference of ca. $0.8 \mathrm{G}$ between the $\alpha$-couplings from unsubstituted exo- and endo-1,3-hydrogens ${ }^{45}$ is typically not resolved.

(43) Fujisawa, J.; Sato, S.; Shimokoshi, K.; Shida, T. J. Phys. Chem. 1985, $89,5841$.

(44) Williams, F. Qin, X.-Z Radiat Phys. Chem 1988, 32, 299.

(45) Linder, R. E.; Winters, D. L.; Ling, A. C. Can. J. Chem. 1976, 54, 1405 . 

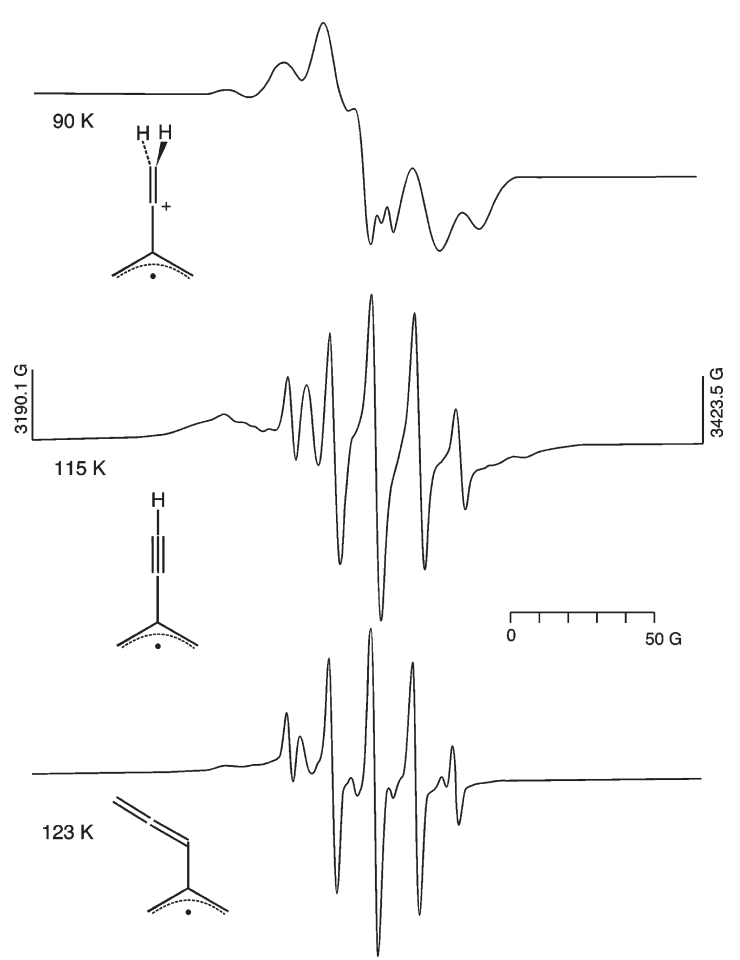

Figure 5. ESR spectrum obtained after ionization by $\gamma$-irradation of $\mathbf{1}$ in $\mathrm{CF}_{2} \mathrm{ClCFCl}_{2}$ at $77 \mathrm{~K}$ and warming of the matrix to (a) $90 \mathrm{~K}$ and (b) $115 \mathrm{~K}$ Spectrum (c), recorded at $123 \mathrm{~K}$ where slow diffusion takes place in this matrix, was obtained after reaction of the allenyl radical with allene, giving rise to the species shown in the figure (cf. text).

In Figure 5c, the spectrum of this product species $\mathbf{B}$ is compared to that of the allylic radical product resulting from the addition of the allenyl radical to the carbon-2 position of allene ${ }^{46}$ (both experiments were carried out in the $\mathrm{CF}_{2} \mathrm{ClCFCl}_{2}$ matrix at ca. $120 \mathrm{~K}$ ). The similarity in the spectral profiles is striking and strongly suggests that species $\mathbf{B}$ contains also an allylic radical center. Furthermore, in view of the almost identical quintet splittings in $\mathbf{A}$ and $\mathbf{B}$, the structures of $\mathbf{A}$ and $\mathbf{B}$ seem to be related through the loss of a proton from $\mathbf{A}$ in an ion-molecule reaction, such that the spin distribution in the allylic moiety is not significantly affected.

Further information about the structure of $\mathbf{A}$ was obtained from its near-IR photolysis carried out in the $\mathrm{CF}_{2} \mathrm{ClCCl}_{3}$ matrix at $83 \mathrm{~K}$ (where the triplet substructure of the ESR signal of $\mathbf{A}$ is also not fully resolved, see Figure 6a). This led to the replacement of the spectrum of $\mathbf{A}$ by a much narrower pattern consisting of a well-resolved 1:2:1 triplet $(a(2 \mathrm{H})=14.6 \mathrm{G}$, see Figure 6b). Identical spectra were obtained (under the same conditions) after ionization and NIR photolysis of $\mathbf{2}$ and, more importantly, after ionization of vinylidenecyclopropane, 4 (see Figure S3 in the Supporting Information).

Firm evidence that the spectrum resulting from the NIR photolysis of $\mathbf{A}$ in the $\mathrm{CF}_{2} \mathrm{ClCCl}_{3}$ matrix (Figure $6 \mathrm{~b}$ ) can indeed be assigned to the unrearranged vinylidenecyclopropane radical cation $4^{\bullet+}$ comes from additional NIR photolysis experiments in the $\mathrm{CF}_{2} \mathrm{ClCFCl}_{2}$ matrix where, in contrast to the $\mathrm{CF}_{2} \mathrm{ClCCl}_{3}$ matrix, ion-molecule reactions can occur as the temperature is raised to $>100 \mathrm{~K}$ (see above). The product observed by ESR after NIR photolysis of species $\mathbf{A}$ in this matrix, followed by annealing to $110 \mathrm{~K}$ shows couplings of $a(4 \mathrm{H})=21.2 \mathrm{G}$ and

(46) Qin, X.-Z. Ph.D. Thesis, University of Tennessee, 1987, pp 142143.

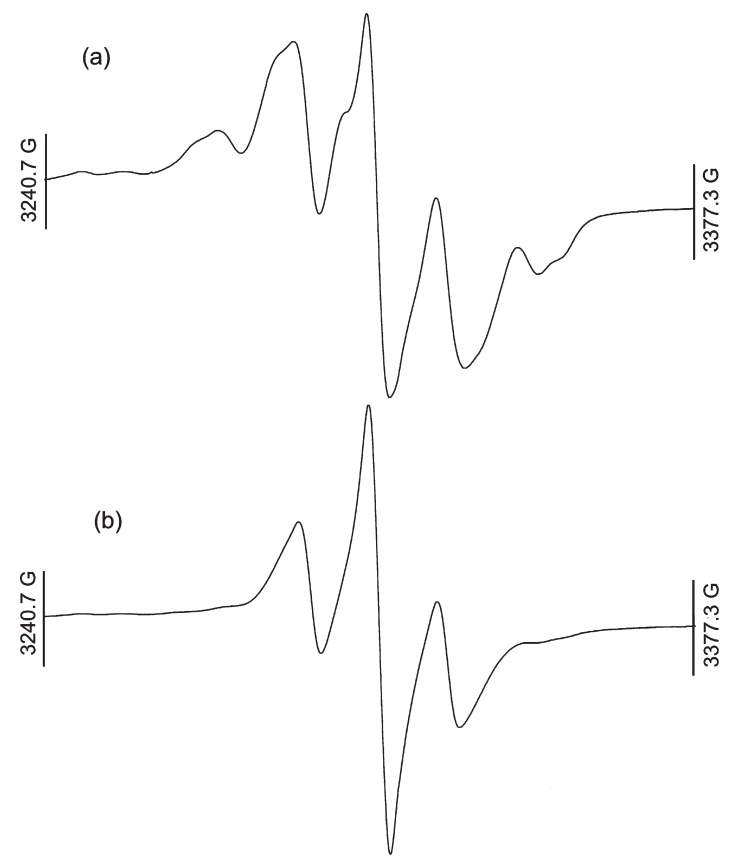

Figure 6. ESR spectrum of $\gamma$-irradiated 1 in $\mathrm{CF}_{2} \mathrm{ClCCl}_{3}$ at $100 \mathrm{~K}$ before (a) and after (b) NIR photolysis for $1.5 \mathrm{~h}$ using a Corning 3962 filter. Spectrum (a) is essentially the same as the quintet observed in Figure 1 except that the additional triplet splitting is only partially resolved in this matrix. Spectrum (b) is identical in all respects to that recorded at the same temperature after $\gamma$-irradiation of a $\mathrm{CF}_{2} \mathrm{ClCCl}_{3}$ solution of 4 .

$a(1 \mathrm{H})=12.2 \mathrm{G}$ (see Figure 7). The latter coupling is characteristic for the terminal $\mathrm{H}$-atom in a propargyl radical (in $\mathrm{MeHC}^{*}-\mathrm{C} \equiv \mathrm{CH}$ it is $11.8 \mathrm{G}^{47}$ ). Thus we conclude that the species obtained after progressive annealing of the photoproduct of $\mathbf{A}$ is the propargylic radical $\mathbf{C}$ obtained by deprotonation at the terminal $\mathrm{CH}_{2}$ group of $\mathbf{4}^{\cdot+}$ (in addition, DFT calculations predict the coupling to the four protons attached to the ring to be $22.0 \mathrm{G}$, in accord with that assignment). Furthermore, the same species $\mathbf{C}$ was also obtained on ionization of $\mathbf{4}$ in the $\mathrm{CF}_{2} \mathrm{ClCFCl}_{2}$ matrix followed by warming to $120 \mathrm{~K}$.

Thus, just as the neutral allylic radical $\mathbf{B}$ provided an important clue to the structure of its parent radical cation $\mathbf{A}$, so the formation of the neutral propargyl radical $\mathbf{C}$ can be directly attributed to a similar proton loss from the vinylidenecyclopropane radical cation $\mathbf{4}^{\circ+}$ in an ion-molecule reaction.

At this point the reader may wonder why $\mathbf{4}^{\cdot+}$ shows coupling to only two of its six protons in its ESR spectrum. As a result of its $D_{2 d}$ symmetry, allene has a degenerate HOMO, and its radical cation is therefore subjected to Jahn-Teller distortion that leads to a reduction of the twisting of the allene moiety to less than $90^{\circ}$ (in allenes of lower symmetry, such as $\mathbf{4}$, the HOMO is no longer degenerate, but distortion still occurs on ionization, due to vibronic coupling of the ground state with a low-lying excited state). ${ }^{48}$ As a consequence, the four protons in the cyclopropylidene moiety become nonequivalent, resulting in two identical pairs, as in the case of the similarly twisted dicyclopropylidene radical cation. ${ }^{49}$

According to DFT calculations, the coupling to two of these protons is $18.2 \mathrm{G}$, whereas that to the other two is only $-2.8 \mathrm{G}$

(47) Kochi, J. K.; Krusic, P. J. J. Am. Chem. Soc. 1970, 92, 4110.

(48) Bally, T.; Müller, B.; Gerson, F.; Qin, X.-Z.; von Seebach, M.; Kozhushkov, S. I.; de Meijere, A.; Borovkov, V. I.; Potashov, P. A J. Phys. Chem. A 2006, 110, 1163.

(49) Gerson, F.; Schmidlin, R.; de Mejiere, A.; Späth, T. J. Am. Chem. Soc. 1995, 117, 8431 

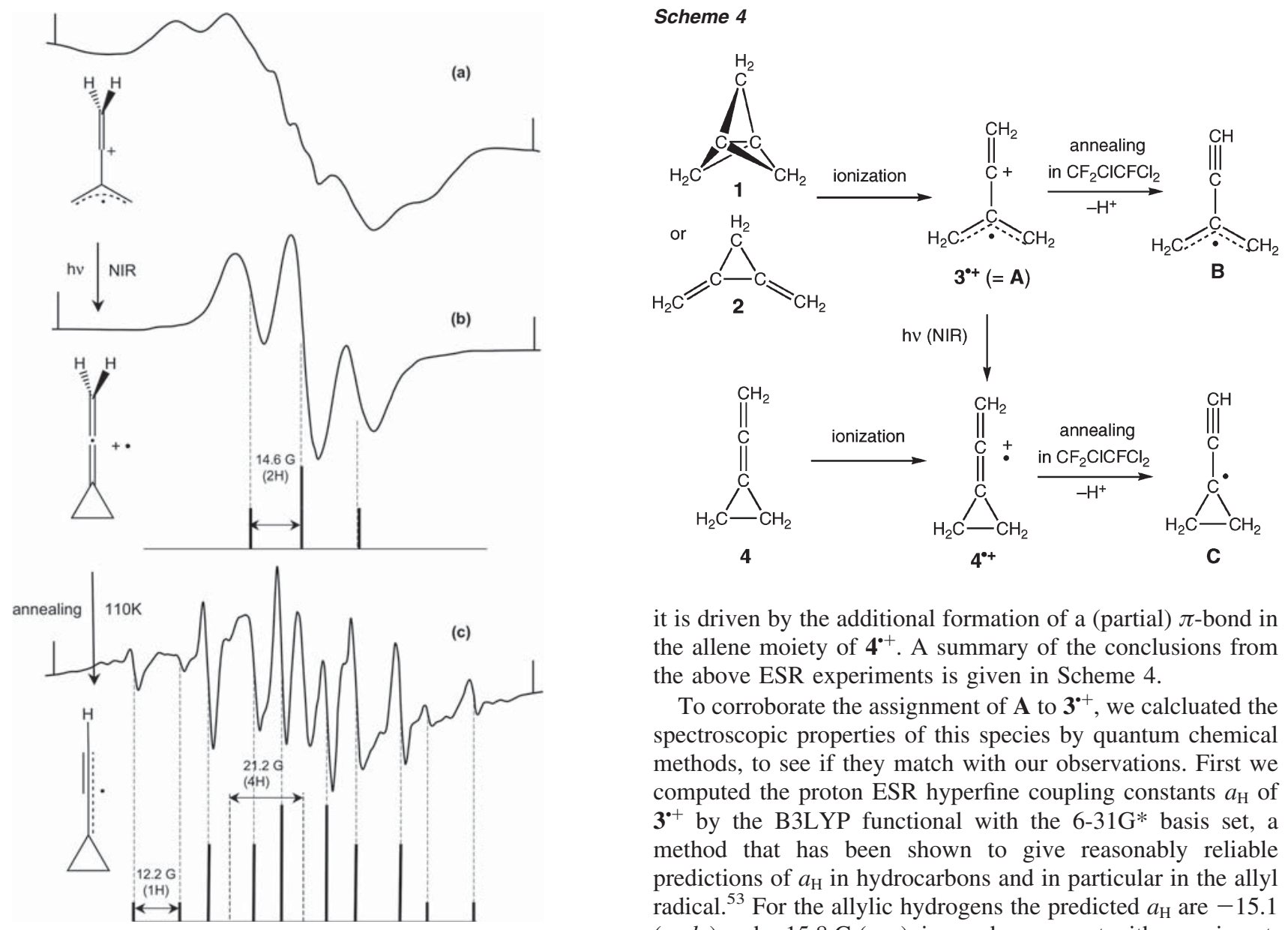

it is driven by the additional formation of a (partial) $\pi$-bond in the allene moiety of $\mathbf{4}^{\cdot+}$. A summary of the conclusions from the above ESR experiments is given in Scheme 4.

To corroborate the assignment of $\mathbf{A}$ to $\mathbf{3}^{\mathbf{}}$, we calcluated the spectroscopic properties of this species by quantum chemical methods, to see if they match with our observations. First we computed the proton ESR hyperfine coupling constants $a_{\mathrm{H}}$ of $3^{\circ+}$ by the B3LYP functional with the $6-31 \mathrm{G}^{*}$ basis set, a method that has been shown to give reasonably reliable predictions of $a_{\mathrm{H}}$ in hydrocarbons and in particular in the allyl radical. ${ }^{53}$ For the allylic hydrogens the predicted $a_{\mathrm{H}}$ are -15.1 (endo) and $-15.8 \mathrm{G}$ (exo), in good agreement with experiment, which showed couplings of ca. $14.8 \mathrm{G}$ for these four protons. The coupling to the allenic protons is predicted to be $-6.4 \mathrm{G}$ (expt, $5.4 \mathrm{G}$ ). Both results point toward a slight overestimation of both $\pi-\sigma$ and $\pi-\pi$ spin polarization by the B3LYP functional. A summary of the measured and calculated hyperfine coupling constants for $\mathbf{3}^{\cdot+}$ and $\mathbf{4}^{\mathbf{+}}$ as well as species $\mathbf{B}$ and $\mathbf{C}$ and some reference values from the literature are given in Table S1 of the Supporting Information.

For modeling the vibrational structure of $\mathbf{3}^{\cdot+}$ we used the same method. On linear scaling of the calculated frequencies by the recommended scaling factor of $0.9513,13$ observed vibrational frequencies of $\mathbf{A}$ were reproduced with an rms deviation of 20.8 $\mathrm{cm}^{-1}$, while the relative intensities of the corresponding IR bands were in good accord with the observed ones (see Table S3 in the Supporting Information for details). On scaling of the force field by the SQM method of Pulay ${ }^{54,55}$ (27 internal coordinates divided into 10 groups whose valence force constants are scaled differently ${ }^{56}$ ) the rms error between calculated and predicted frequencies dropped to $7.1 \mathrm{~cm}^{-1}$ (see Supporting Information), leaving little doubt that the IR assigment is indeed correct.

To model the very peculiar electronic absorption spectrum that we would like to attribute to $\mathbf{3}^{\mathbf{}}$, we explored the electronic structure of this species. As the ESR spectrum shows, the spin is mainly located in the allylic moeity and so is therefore the singly occupied MO. Figure 8 shows the $\pi$-MOs of $3^{\circ+}$ that

(50) Bally, T.; Müller, B.; Williams, F.; Pappas, R. Manuscript in preparation

(51) Woodward, R. B.; Hoffmann, R. The Conservation of Orbital Symmetry; Verlag Chemie: Weinheim, 1970.

(52) Longuet-Higgins, H. C.; Abrahamson, E. W. J. Am. Chem. Soc. 1965, $87,2045$.

(53) Batra, R.; Giese, B.; Spichty, M. J. Phys. Chem. 1996, 100, 18371.

(54) Pulay, P.; Fogarasi, G.; Pang, F.; Boggs, J. E. J. Am. Chem. Soc. 1979, $101,2550$.

(55) Bally, T.; Tang, W.; Zhang, Y. J. Am. Chem. Soc. 1993, 97, 43645.

(56) Müller, B. Ph.D. disseration No. 1299, University of Fribourg, 2000. 


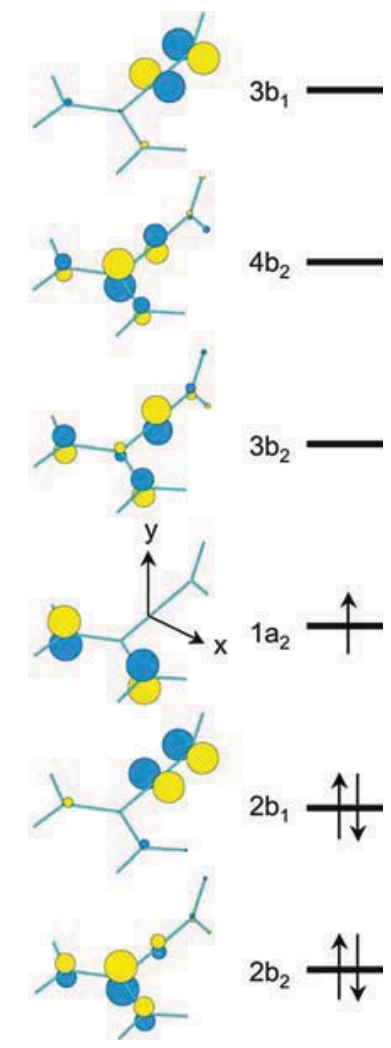

Figure 8. Molecular orbitals of $\mathbf{3}^{\boldsymbol{*}}$ that consistute the active space used in the CASSCF calculations shown in Table 1.

Table 1. Excited States of $\mathbf{3}^{\cdot+}$ by CASPT2 Calculations

\begin{tabular}{|c|c|c|c|c|}
\hline \multirow[b]{2}{*}{ states } & \multicolumn{3}{|c|}{ CASPT2 } & \multirow{2}{*}{$\frac{\text { CASSCF }^{a}}{\text { configurations }^{c}}$} \\
\hline & $\mathrm{eV}$ & $\mathrm{nm}$ & $f^{b}$ & \\
\hline $1^{2} \mathrm{~A}_{2}$ & & & & $90 \%\left(1 a_{2}\right)^{1}$ \\
\hline $1^{2} \mathrm{~B}_{2}$ & 0.80 & 1543 & 0.007 & $81 \% 1 \mathrm{a}_{2} \rightarrow 3 \mathrm{~b}_{2}$ \\
\hline $1^{2} \mathrm{~B}_{1}$ & 3.64 & 341 & $2 \times 10^{-6}$ & $\begin{array}{l}60 \%\left[1 \mathrm{a}_{2} \rightarrow 4 \mathrm{~b}_{2}+2 \mathrm{~b}_{1} \rightarrow 4 \mathrm{~b}_{2}\right] \\
16 \% 2 \mathrm{~b}_{1} \rightarrow 1 \mathrm{a}_{2}\end{array}$ \\
\hline $2^{2} \mathrm{~B}_{2}$ & 5.18 & 239 & 0.006 & $\begin{array}{l}51 \% 1 \mathrm{a}_{2} \rightarrow 4 \mathrm{~b}_{2} \\
31 \% 2 \mathrm{~b}_{2} \rightarrow 1 \mathrm{a}_{2}\end{array}$ \\
\hline $2^{2} \mathrm{~A}_{2}$ & 5.32 & 233 & $6 \times 10^{-4}$ & $85 \%\left[1 \mathrm{a}_{2} \rightarrow 6 \mathrm{~b}_{1}+5 \mathrm{~b}_{1} \rightarrow 1 \mathrm{a}_{2}\right]$ \\
\hline $2^{2} \mathrm{~B}_{1}$ & 5.36 & 231 & $1 \times 10^{-6}$ & $75 \% 1 a_{2} \rightarrow 6 b_{1}$ \\
\hline $3^{2} \mathrm{~A}_{2}$ & 5.87 & 211 & 0.572 & $\begin{array}{l}66 \% 2 \mathrm{~b}_{2} \rightarrow 4 \mathrm{~b}_{2} \\
15 \%\left[1 \mathrm{a}_{2} \rightarrow 4 \mathrm{~b}_{2}+2 \mathrm{~b}_{2} \rightarrow 1 \mathrm{a}_{2}\right]\end{array}$ \\
\hline $3^{2} \mathrm{~B}_{2}$ & 6.20 & 200 & 0.226 & $\begin{array}{l}61 \%\left[1 \mathrm{a}_{2} \rightarrow 4 \mathrm{~b}_{2}+5 \mathrm{~b}_{1} \rightarrow 3 \mathrm{~b}_{2}\right] \\
11 \%\left[2 \mathrm{~b}_{2} \rightarrow 3 \mathrm{~b}_{1}+1 \mathrm{a}_{2} \rightarrow 3 \mathrm{~b}_{1}\right]\end{array}$ \\
\hline
\end{tabular}

${ }^{a}$ The active space comprises the MOs shown in Figure 8. Averaging was done over three ${ }^{2} \mathrm{~A}_{2}$, three ${ }^{2} \mathrm{~B}_{1}$, and four ${ }^{2} \mathrm{~B}_{2}$ states, respectively. Reference weights for the zero-order CASSCF wavefunctions were $>80 \%$ for all CASPT2 states. ${ }^{b}$ Oscillator strength for electronic transition. ${ }^{c}$ In terms of excitations between the MOs depicted in Figure 8.

were all included in the active space of a CASSCF/CASPT2 calculation, the results of which are shown in Table 1.

This table shows that, in contrast to most radical cations, the lowest energy transition (predicted at $0.803 \mathrm{eV}$ or $1543 \mathrm{~nm}$ ) involves excitation of the unpaired electron (which occupies the purely allylic $\mathrm{a}_{2}-\mathrm{MO}$ ) into a virtual MO. Following this transition there is a gap that spans the entire visible and the
near-UV range (barring a symmetry-forbidden transition at 365 $\mathrm{nm}$ that is not listed in Table 1), until a pair of very strong transitions follows at 211 and $200 \mathrm{~nm}$ that we could, however, not see because this region is masked by absorptions of neutral 1. Thus, despite its very low-lying first excited state, $\mathbf{3}^{\mathbf{+}}$ is entirely colorless, but the predictions listed in Table 1 are in good agreement with the observation of a single band of species A at ca. $1400 \mathrm{~nm}(0.88 \mathrm{eV})$ and no other absorptions above $250 \mathrm{~nm}$ (cf. Figure 3, lower part).

Mechanism of the Spontaneous Decay of $1^{\cdot+}$ to $3^{\cdot+}$. To elucidate the mechanism of this surprising reaction, we modeled the potential surface that connects $\mathbf{1}^{\mathbf{0}^{+}}$to $\mathbf{3}^{+}$by quantum chemical calculations (in what follows, all relative energies are from single-point CCSD(T)/cc-pVTZ calculations at the B3LYP/ 6-31G* optimized geometries).

As expected, the $D_{3 h}$ structure of $\mathbf{1}^{\cdot+}$ is a potential energy minimum at the UHF, ROHF, UMP2, and QCISD levels, with bond lengths that differ only little from those of $\mathbf{1}$. However, at the $\mathrm{B} 3 \mathrm{LYP} / 6-31 \mathrm{G}^{*}$ level, the $D_{3 h}$ structure is a transition state having a degenerate imaginary normal mode with a frequency of $-202 \mathrm{~cm}^{-1}$ depicted in Figure 9 (at the other levels of theory the same mode has a positive frequency, e.g., $+195 \mathrm{~cm}^{-1}$ by QCISD/6-31G*).

Following component (a) of that mode, which entails a distortion to $C_{s}$ symmetry, leads to a marginally more stable potential energy minimum where one of the lateral bonds has increased its length by $0.1 \AA$. Further stretching of that bond to $1.86 \AA$ leads to a transition state, $1.15 \mathrm{kcal} / \mathrm{mol}$ above the shallow minimum, at the far side of which the bond undergoes complete cleavage to form a species $\mathbf{5}^{\mathbf{+}}$ that may be described as a methylenebicyclobutyl radical cation (Figure 10, the SOMO of $\mathbf{5}^{\mathbf{+}}$ is shown in Figure 9).

Stretching the long central $\mathrm{C}-\mathrm{C}$ bond in $\mathbf{5}^{\mathbf{+}}$ leads to planarization of the carbon frame to give the radical cation of

(a)
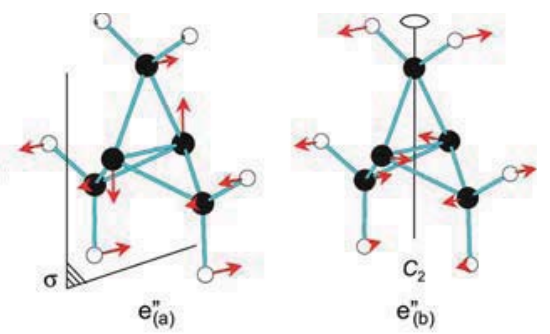

(b)
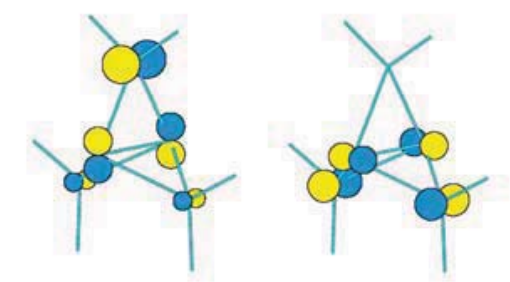

(c)

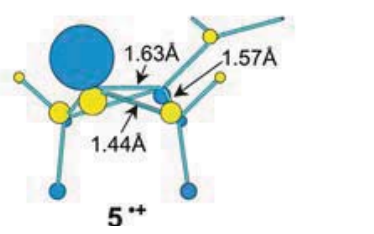

Figure 9. (a) The two compontents of the $\mathrm{e}^{\prime \prime}$ imaginary normal mode of 1 (calculated in $D_{3 h}$ symmetry at the B3LYP/6-31G* level; the symmetry elements that remain on distortion along each component of the $\mathrm{e}^{\prime \prime}$ mode are indicated). (b) The two components of the $\mathrm{e}^{\prime \prime} \mathrm{MO}$ of $\mathbf{1}$. (c) The species $\mathbf{5}^{\cdot+}$ that results from the distortion of $\mathbf{1}^{\cdot+}$ along component (a) of the $\mathrm{e}^{\prime \prime}$ mode (the MO is the SOMO of $\mathbf{5}^{\mathbf{}}$ ). 


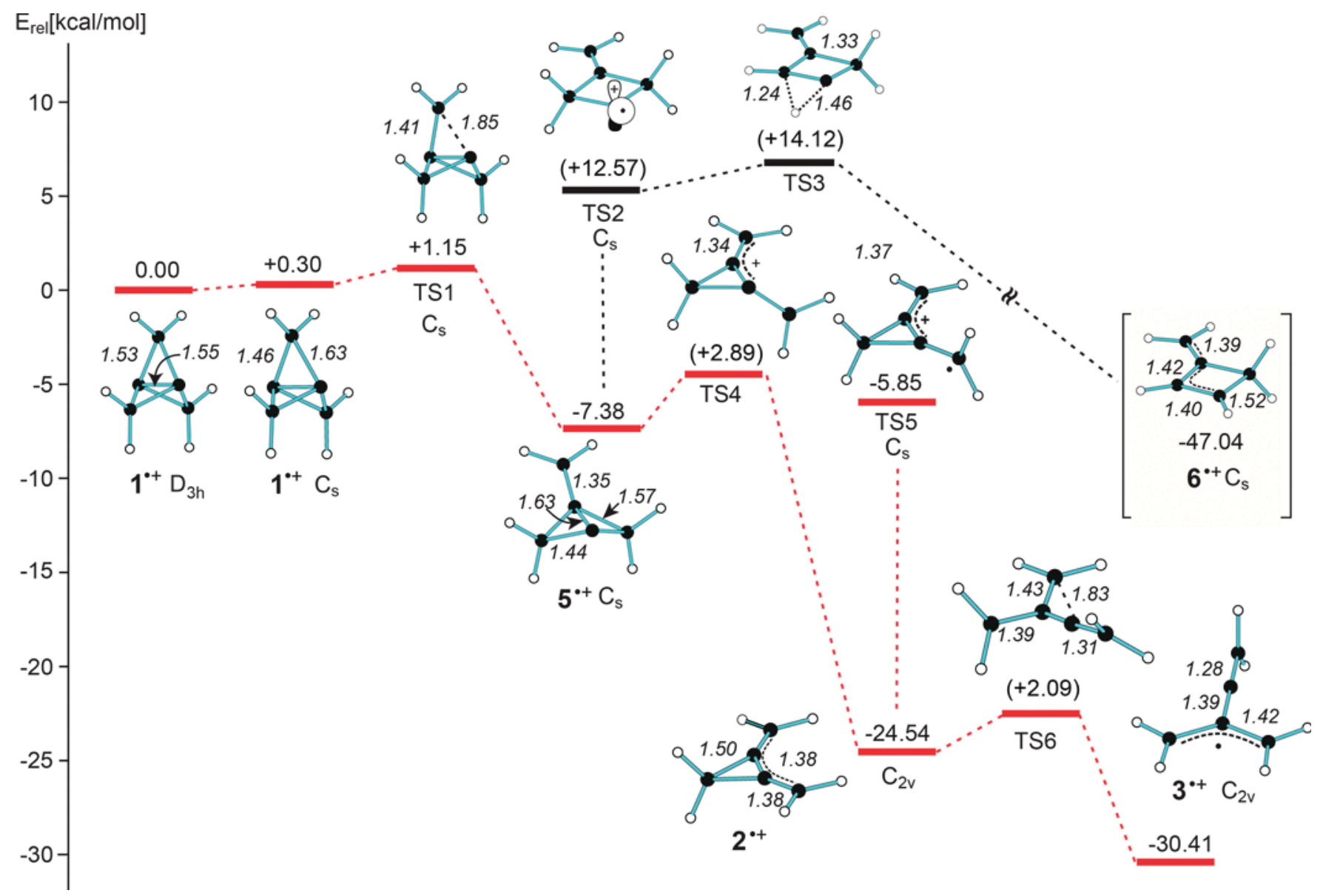

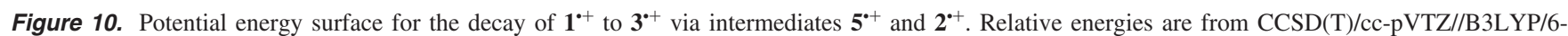
$31 \mathrm{G}^{*}$ calculations and include the contributions from zero-point vibrational energies. Numbers in parentheses indicate energies of transition states TS1-TS6 relative to the preceding minima. Italic numbers indicate $\mathrm{C}-\mathrm{C}$ bond lengths in $\AA$. If no symmetry is indicated, it is $C_{1}$. The same figure, complemented by relative CASPT2 energies, is given as Figure S7 of the Supporting Information.

methylenecyclobutylidene, which represents actually the transition state TS2 for inversion of the bicyclobutyl moiety, 12.57 $\mathrm{kcal} / \mathrm{mol}$ above $\mathbf{5}^{\circ}$. Only $1.54 \mathrm{kcal} / \mathrm{mol}$ above that structure lies another transition state (TS3 in Figure 10) for a [1,2] shift of one of the hydrogen atoms to the (carbenoid) apical carbon atom, on the far side of which the species decays in a highly exothermic process to the radical cation of methylenecyclobutene, $\mathbf{6}^{\mathbf{}}$. We will return to this species in a separate paper $^{50}$ that will deal with the assignment of the bands that cannot be attributed to $\mathbf{1}^{\mathbf{+}}$ in the spectra shown in Figures 3 and 4 . In the present context it suffices to note that a barrier of $14 \mathrm{kcal} / \mathrm{mol}$ is probably too high to be crossed by a thermalized species at $7 \mathrm{~K}$, so another decay channel must be available to $\mathbf{5}^{+}$.

Such a channel opens on stretching the second longest (1.57 $\AA$ ) lateral bond in $\mathbf{5}^{\mathbf{}}$, which leads, at $1.93 \AA$, to a transition state TS4 that lies less than $3 \mathrm{kcal} / \mathrm{mol}$ above $\mathbf{5}^{\mathbf{}}$. On the far side of TS4 the species decays to the radical cation of dimethylenecyclopropane, $\mathbf{2}^{\bullet+}$. TS4 actually shows some structural similarity to TS5, the transition state for rotation of an exocyclic $\pi$-bond of $\mathbf{2}^{-+}$. The barrier for this rotation is surprisingly low $(18.7 \mathrm{kcal} / \mathrm{mol})$, which is due on the one hand to the weakening of that $\pi$-bond by ionization and on the other hand to the allylic resonance that TS5 enjoys. TS4, which lies only $1.36 \mathrm{kcal} / \mathrm{mol}$ above TS5, appears to profit also from the latter stabilization, and we believe that this is the reason why the barrier for decay of $\mathbf{5}^{\mathbf{}+}$ by cleavage of a lateral bond is so low.

Although the minimum energy structure of $\mathbf{2}^{\mathbf{}}$ is slightly distorted to $C_{2}$ symmetry (by twisting the two exocyclic $\mathrm{C}=\mathrm{C}$ bonds by ca. $3^{\circ}$ ), this structure appears as a stable potential energy minimum. ${ }^{57}$ Nevertheless, stretching of one of the two lateral bonds requires surprisingly little energy, and the transition state for cleavage of this bond was found to lie only $2.09 \mathrm{kcal} /$ mol above $\mathbf{2}^{\cdot+}$, which therefore seems to decay to the observed product, $\mathbf{3}^{\mathbf{+}}$, in a nearly barrierless process. Thus, to sum up this section, the radical cation of [1.1.1]propellane, $\mathbf{1}^{\mathbf{}+}$, decays spontaneously, by consecutive cleavage of three lateral bonds, via two fleeting intermediates, to the allylic species $3^{\cdot+}$. An illustration of the potential surface that leads from $\mathbf{1}^{\cdot+}$ to $3^{\cdot+}$ is given in Figure 10.

We will now turn to the question of why the radical cation of [1.1.1]propellane undergoes such a facile distortion and why the barriers for further decay to $3^{++}$are so surprisingly low.

(57) The finding of $\mathbf{2}^{++}$as a seemingly stable product of the decay of $\mathbf{1}^{\mathbf{+}}$ led us to examine whether this species might be responsible for the non-bleachable bands in the optical (Figure 3) and the IR spectrum (Figure 4) we had observed after ionization of $\mathbf{1}^{\cdot+}$. However, complete lack of accord with the calculated electronic (CASPT2) and vibrational (B3LYP) spectra for $\mathbf{2}^{+}$(see separate paper, ref 50) convinced us that this is not the case. 


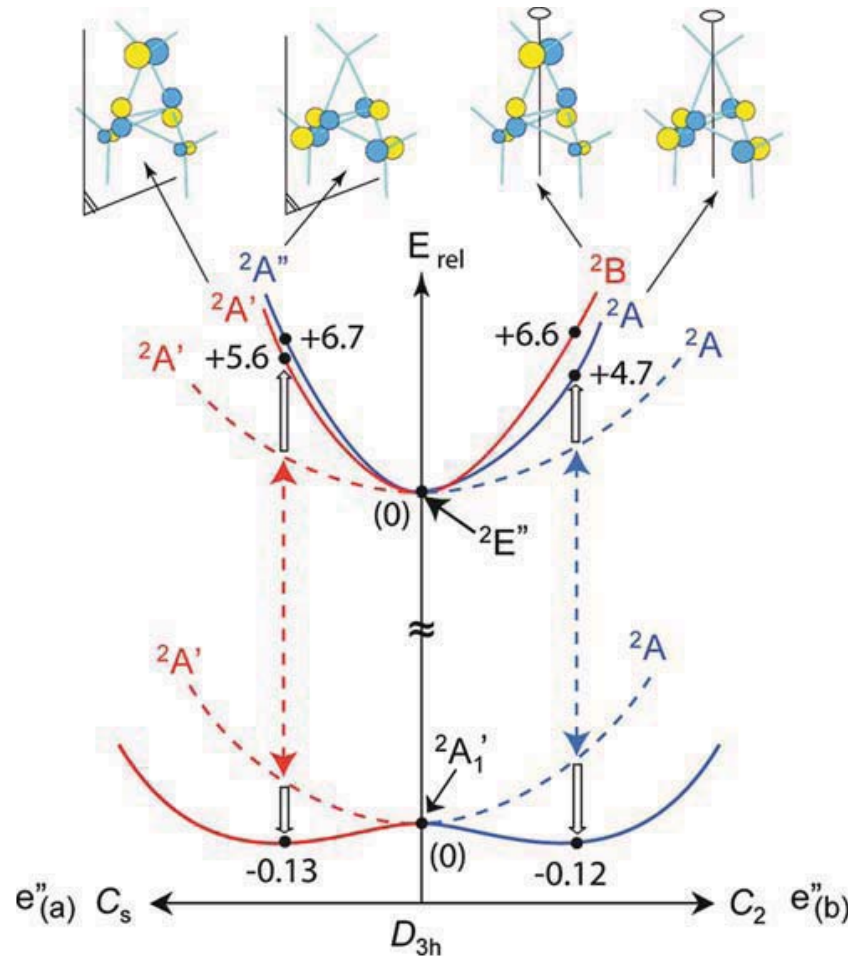

Figure 11. Distortions of $\mathbf{1}^{\mathbf{+}}$ along the two components of the $\mathrm{e}^{\prime \prime}$ mode Dashed lines denote (qualitative) potential surfaces in the absence of vibronic coupling, solid line with vibronic coupling. Numbers denote relative energies from (TD)B3LYP/6-31G* calculations.

Role of Vibronic Coupling in Destabilizing $\mathbf{1}^{\bullet+}$. The $\mathrm{e}^{\prime \prime}$ normal mode along which $\mathbf{1}^{\cdot+}$ distorts so easily (even spontaneously on the B3LYP potential surface) has a frequency of $+1167 \mathrm{~cm}^{-1}$ in neutral $\mathbf{1}$, and to cleave a lateral bond in $\mathbf{1}$ (to form 3 -methylenecyclobutylidene) requires over $40 \mathrm{kcal} / \mathrm{mol}$. What is it that makes this process become so much more facile after ionization? The answer to this question can be found by considering the potential surfaces of the excited states and how these interact, upon suitable distortion, with the ground state, ${ }^{25}$ as illustrated in Figure 11.

For $\mathbf{1}^{-+}$in $D_{3 h}$ symmetry, the singly occupied MO (SOMO) in the ground state $\left(\mathrm{a}_{1}{ }^{\prime}\right)$ and that in the first excited state $\left(\mathrm{e}^{\prime \prime}\right.$, cf. Figure 9) belong to different irreducible representations, and hence the corresponding states cannot mix. Distortion along component (a) of the $\mathrm{e}^{\prime \prime}$ vibration reduces the symmetry from $D_{3 h}$ to $C_{s}$, i.e., the ${ }^{2} \mathrm{E}^{\prime \prime}$ state splits into a ${ }^{2} \mathrm{~A}^{\prime}$ state (which has now the same symmetry as the ground state in $C_{s}$ and can hence mix with it) and $\mathrm{a}^{2} \mathrm{~A}^{\prime \prime}$ state (which cannot mix with the ground state). Similarly, distortion along component (b) of the $\mathrm{e}^{\prime \prime}$ vibration reduces the symmetry from $D_{3 h}$ to $C_{2}$, i.e., the ${ }^{2} \mathrm{E}^{\prime \prime}$ state splits into a ${ }^{2} \mathrm{~A}$ state (which has now the same symmetry as the ground state) and ${ }^{2} \mathrm{~B}$ state (which cannot mix with the ground state). Thus, in both cases only one of the "branches" of the surfaces for distortion of the excited state to $C_{s}$ or $C_{2}$ symmetry, respectively, is effective in undergoing vibronic coupling to the ground state, while the other is not. Note that the SOMO is not the same in the A branch (in $C_{2}$ ) and in the $\mathrm{A}^{\prime}$ branch (in $C_{s}$ ) that couple to the ground state.

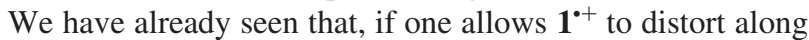
component (a) of the $\mathrm{e}^{\prime \prime}$ mode, this leads to a slight stabilization, and to a potential energy minimum (by B3LYP/6-31G*). Allowing distortion along component (b), i.e., descent to $C_{2}$ symmetry, leads to a similar stabilization but to a flat saddle

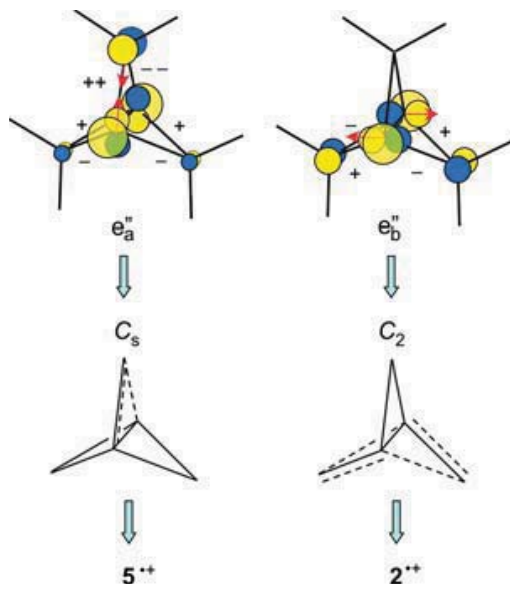

Figure 12. Schematic representation of the transition density arising from the interaction of the ${ }^{2} \mathrm{~A}_{1}$ ground state with the two components of the ${ }^{2} \mathrm{E}^{\prime \prime}$ excited state of $\mathbf{1}^{\cdot+}$, and the weakening of bonds it induces.

point on the B3LYP potential surface. The corresponding imaginary mode resembles component (a) of the $\mathrm{e}^{\prime \prime}$ mode and it points to the slightly lower-lying $C_{\mathrm{s}}$ minimum of $\mathbf{1}^{\mathbf{}+}$ to which the species decays upon unconstrained geometry optimization.

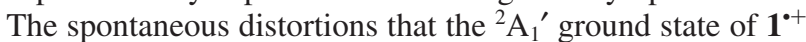
undergoes (at the B3LYP/6-31G* level) are therefore a consequence of its mixing, through deformations along the two components of an $\mathrm{e}^{\prime \prime}$ mode, with the first ${ }^{2} \mathrm{E}^{\prime \prime}$ excited state, which according to photoelectron spectroscopy ${ }^{13}$ (see Figure 1) lies only $1.56 \mathrm{eV}$ above the ground state.

Figure 11 shows that the above deformations do not lead to a pronounced splitting of the degeneracy nor to a stabilization of the lower component of the ${ }^{2} \mathrm{E}^{\prime \prime}$ excited state, in contrast to the $\mathrm{e}^{\prime}$ modes that lead to structures of $C_{2 v}$ symmetry and to a pronounced Jahn-Teller (JT) effect ${ }^{24}$ (see Figure S6 in the Supporting Information). However, the pair of excited states that result from this JT distortion $\left({ }^{2} \mathrm{~A}_{2}\right.$ and $\left.{ }^{2} \mathrm{~B}_{1}\right)$ both still have a symmetry different from that of the ground sate $\left({ }^{2} \mathrm{~A}_{1}\right)$, and hence JT distortions do not entail a coupling of the ground state to the ${ }^{2} \mathrm{E}^{\prime \prime}$ excited state.

An alternative way to look at this vibronic coupling effect is to follow the development of the vibrationally induced transition density ${ }^{21,58-61}$ resulting from the mixing of the $\mathrm{a}_{1}{ }^{\prime}$ orbital with the two components of the $\mathrm{e}^{\prime \prime} \mathrm{MO}$ of $\mathbf{1}^{\cdot+}$, as illustrated in Figure 12. Considering first the $\mathrm{a}_{1}{ }^{\prime}-\mathrm{e}^{\prime \prime}{ }_{\text {(a) }}$ interactions, it can be seen that the resulting increase $(+)$ and decrease $(-)$ of electron density are symmetric with respect to the vertical plane shown on the left-hand side of Figure 11, thus giving rise to a transition density of $C_{s}$ symmetry. The nuclei respond to this transition density mainly by shortening one and elongating the other of the apical $\mathrm{C}-\mathrm{C}$ bonds (at the same time the pair of $\mathrm{C}-\mathrm{C}$ bonds adjacent to the shortened bond lengthen and those adjacent to the elongated bond shorten slightly, but this effect will be weaker). This deformation, which corresponds to that along the

(58) Longuet-Higgins, H. C. Proc. R. Soc. A 1956, 235, 537.

(59) Bader, R. F. W. Can. J. Chem. 1962, 40, 1164.

(60) Salem, L. Chem. Phys. Lett. 1969, 3, 99.

(61) Vibronic coupling in radicals is suitably enhanced, compared to closedshell molecules, by the relatively small energy gap $(\approx 0.5-1.5 \mathrm{eV})$ that usually exists between their ground state and those excited states that arise by promotion of an electron from the doubly occupied to the close-lying singly occupied MO. On the other hand, excited states of closed-shell molecules invariably arise by promotion of electrons into virtual MOs, which involves typically much larger energy gaps $(\approx 4 \mathrm{eV})$. 
$\mathrm{e}^{\prime \prime}$ (a) normal mode in Figure 9, leads to the initial formation of $\mathbf{5}^{+}$in the stepwise process that ultimately yields $\mathbf{3}^{\mathbf{}}$.

Turning to the $\mathrm{a}_{1}^{\prime}-\mathrm{e}^{\prime \prime}$ (b) interaction, one finds by analogy that a pair of unconnected $\mathrm{C}-\mathrm{C}$ bonds in $\mathbf{1}^{\mathbf{+}}$ undergo weakening while the opposite diagonal pair of bonds is strengthened. If this distortion (which corresponds to that along the $\mathrm{e}^{\prime \prime}$ (b) normal mode) is carried further, it leads to the simultaneous cleavage of $t w o$ bonds, i.e., the direct formation of $\mathbf{2}^{\mathbf{}}$. We have followed this distortion computationally, but unsurprisingly the $C_{2}$ transition state that is reached along this coordinate lies much higher than that leading to $\mathbf{5}^{\mathbf{+}}$ by cleavage of only one bond.

Further Rearrangements. The case of $\mathbf{1}^{\mathbf{}}$ illustrates well the importance of vibronic coupling in weakening normally robust bonds in radical cations. Thus we might ask whether (or to what extent) this effect is also responsible for the facile further decay on the way to the final observed product, $\mathbf{3}^{\mathbf{}}$. What is required for vibronic coupling to be effective is a low-lying excited state (which does not necessarily need to be the first one $!^{62}$ ) that can couple to the ground state by a normal mode of suitable symmetry $^{63}$ and has a moderate force constant, conditions that are well fulfilled in $\mathbf{1}^{\mathbf{}}$.

If we turn to $\mathbf{5}^{\mathbf{}}$ we note that the ground state has ${ }^{2} \mathrm{~A}^{\prime}$ symmetry (cf. Figure 9c), so a ${ }^{2} \mathrm{~A}^{\prime \prime}$ state is needed to induce loss of $C_{s}$ symmetry. TD-DFT calculations on $\mathbf{5}^{\mathbf{}}$ predict that the lowest such state lies $4.35 \mathrm{eV}$ above the ground state, which makes effective coupling of the two states very unlikely. Indeed, we have argued above that it actually is the gain in allylic resonance energy, already at the transition state TS4, that drives the decay of $\mathbf{5}^{\mathbf{+}}$ to $\mathbf{2}^{\mathbf{*}}$.

More intriguing is the case of $\mathbf{2}^{\mathbf{*}}$, where a normally quite robust $\mathrm{C}\left(\mathrm{sp}^{2}\right)-\mathrm{C}\left(\mathrm{sp}^{3}\right) \sigma$-bond breaks readily to yield the final product, $\mathbf{3}^{+}$, in a process that is exothermic by less than $6 \mathrm{kcal} /$ mol. In an effort to understand the electronic structure of $\mathbf{2}^{+}$ and its possible consequences on the surprising reactivity of $\mathbf{2}^{\mathbf{}}$, we measured its photoelectron spectrum (Figure 13) and assigned it with the help of DFT calculations.

These calculations leave no doubt that the highest two molecular orbitals are $\pi$-MOs of $a_{2}$ and $b_{1}$ symmetry, respectively, and are followed by two $\sigma$-MOs of the Walsh type to which the shoulder at 10.9 and the peak at $11.5 \mathrm{eV}$ may be attributed. ${ }^{63}$ The ${ }^{2} \mathrm{~B}_{1}$ first excited state is separated from ${ }^{2} \mathrm{~A}_{2}$ the ground state by only $1.4 \mathrm{eV}$, and the modes of $\mathrm{a}_{2} \times \mathrm{b}_{1}=\mathrm{b}_{2}$ symmetry, which are apt to couple those two states, would in principle be capable of inducing asymmetric distortions of a kind that may eventually lead to cleavage of a lateral bond in $\mathbf{2}^{\mathbf{*}}$. To see whether this is the case, we determined, by a $(3 \times$ 3) CASSCF calculation, the derivative coupling vector (i.e., the nuclear displacements that lead to optimal coupling) of the ${ }^{2} \mathrm{~A}_{2}$ and the ${ }^{2} \mathrm{~B}_{1}$ states. This vector (shown in Figure 13) corresponds to the $\mathrm{b}_{2}$ asymmetric $\mathrm{C}=\mathrm{C}$ stretching mode (which has also some contributions from $\mathrm{CH}_{2}$ scissoring). The frequency of this mode is indeed lowered from $1711 \mathrm{~cm}^{-1}$ in 2 to $1364 \mathrm{~cm}^{-1}$ in $\mathbf{2}^{\mathbf{*}}$, whereas the frequency of the symmetric $\mathrm{C}=\mathrm{C}$ stretching mode decreases only by $53 \mathrm{~cm}^{-1}$ on ionization.

Apart from affecting the lengths of the exocyclic $\mathrm{C}-\mathrm{C}$ bonds, distortions along this $b_{2}$ mode also change the lengths of the lateral ring bonds, i.e., that which is geminal to the shortening

(62) Bally, T.; Bernhard, S.; Matzinger, S.; Roulin, J.-L.; Sastry, G. N.; Truttmann, L.; Zhu, Z.; Marcinek, A.; Adamus, J.; Kaminski, R.; Gebicki, J.; Williams, F.; Chen, G.-F.; Fülscher, M. P. Chem.-Eur. J. 2000, 5, 858 .

(63) Modes that couple two states must belong to the irreducible representation that results from the direct product of those of the two states.

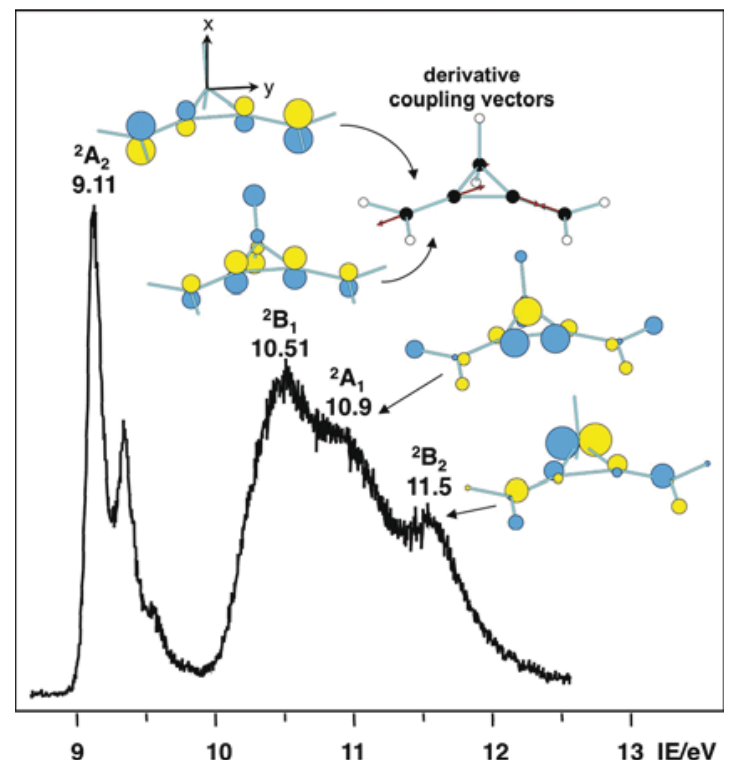

Figure 13. Photoelectron spectrum of 2, highest four occupied MOs, and derivative coupling vectors for the coupling of the ${ }^{2} \mathrm{~A}_{2}$ and the ${ }^{2} \mathrm{~B}_{1}$ states.

Scheme 5

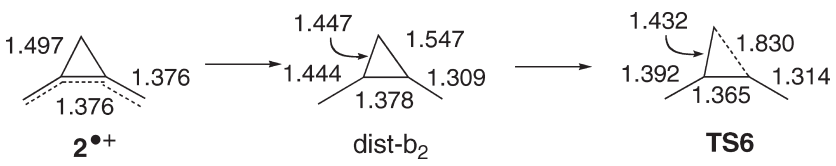

exocyclic bond lengthens, while the other one shortens (see structure "dist-b ${ }_{2}$ " in Scheme 5, which is attained by following the derivative coupling vector shown in Figure 13). Similar distortions occur on the way from $2^{\cdot+}$ to TS6, which indicates that these distortions are indeed facilitated by vibronic coupling between the ${ }^{2} \mathrm{~A}_{2}$ ground state of $2^{\cdot+}$ and its ${ }^{2} \mathrm{~B}_{1}$ excited state.

However, with a (reduced) frequency of $1364 \mathrm{~cm}^{-1}$ for this mode, such distortions are still far from being spontaneous. Hence this mode cannot represent the only perturbation leading to the rearrangement of $\mathbf{2}^{+}$, one possibility being that another asymmetric mode of lower frequency takes over the cleavage process at slightly distorted geometries.

We have seen previously that higher excited states of a radical cation may induce or facilitate distortions of the ground state via vibronic coupling. ${ }^{62}$ At this point we may recall that the equilibrium geometry of $\mathbf{2}^{\mathbf{}+}$ does not have the $C_{2 v}$ symmetry of neutral 2 but was found to distort slightly to $C_{2}$, by following an asymmetric twisting mode of the exocyclic $\mathrm{CH}_{2}$ groups. This $a_{2}$ mode has a frequency of $780 \mathrm{~cm}^{-1}$ in neutral 2 , and its lowering (to $-66 \mathrm{~cm}^{-1}$ ) in $2^{\cdot+}$ points toward vibronic coupling. Indeed, $\mathrm{a}_{2}$ modes are apt to couple the ${ }^{2} \mathrm{~A}_{2}$ ground state to the ${ }^{2} \mathrm{~A}_{1}$ excited state, and this particular twisting mode seems to be very effective at that (unfortunately we are unable to calculate derivative coupling vectors for higher excited states). Following this very soft mode beyond the equilibrium structure will lead to the $\sigma-\pi$ mixing that is prerequisite for cleavage of a lateral $\sigma$-bond, Thus, it could be that the combined effects of vibronically coupling the ${ }^{2} \mathrm{~B}_{1}$ and the ${ }^{2} \mathrm{~A}_{1}$ excited states of $\mathbf{2}^{\cdot+}$ to its ${ }^{2} \mathrm{~A}_{2}$ ground state are responsible for lowering the barrier for its rearrangement to $\mathbf{3}^{\bullet+}$.

Another possible reason for the occurrence of a low-lying transition state would be an avoided state crossing (conical intersection) that occurs near that transition state. We have examined this possibility, by optimizing the geometries of the 


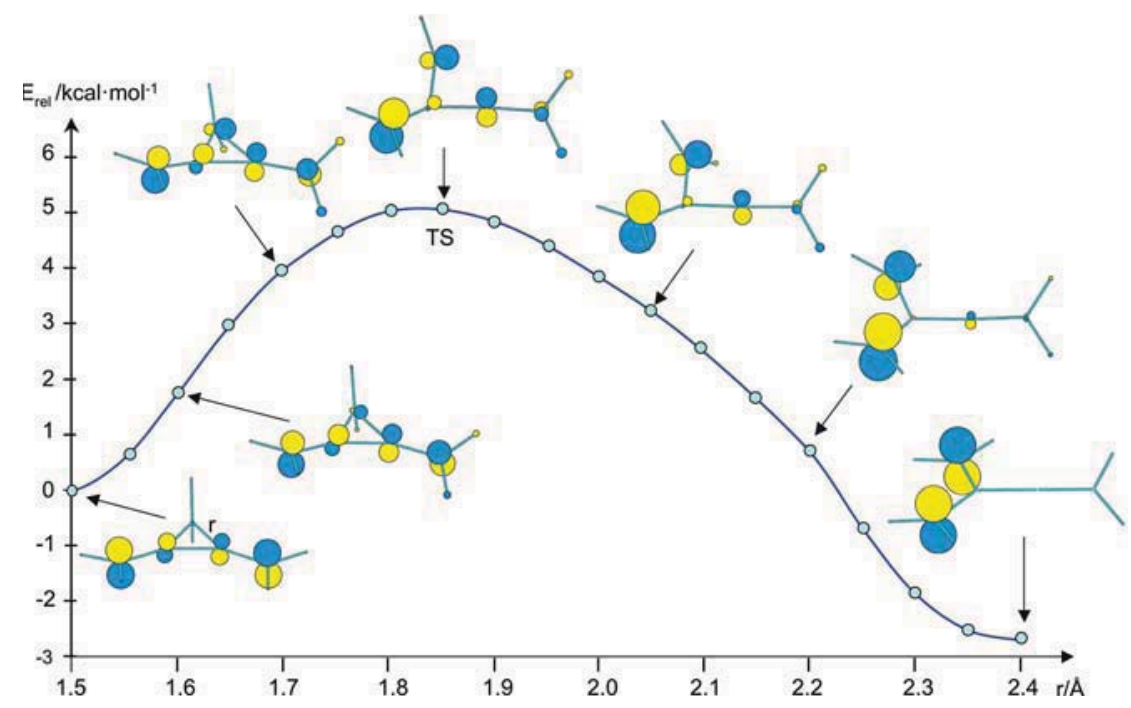

Figure 14. Energy profile and evolution of the SOMO for the $\mathbf{2}^{\cdot+} \rightarrow \mathbf{3}^{\cdot+}$ rearrangement (from B3LYP/6-31G* calculations).

lowest (excited) states of all four symmetries (see Figure S5 in the Supporting Information). However, none of those excited states falls below the ${ }^{2} \mathrm{~A}_{2}$ state or correlates with the ground state of $3^{\cdot+}$ (at TS6 the lowest excited state lies $2.36 \mathrm{eV}$ above the ground state which practically excludes a conical intersection anywhere near TS6).

Finally, in the hope of obtaining a hint as to the precise nature of this surprising rearrangement, we followed the evolution of the SOMO in the course of the reaction (Figure 14). This shows clearly the necessity of $\sigma-\pi$ mixing in promoting the reaction (see above), but there are no unusual or abrupt changes in the nodal properties of the wave function, which could indicate a switching of states. Thus, it is not immediately obvious why the lateral bond in $\mathbf{2}^{\mathbf{}+}$ breaks as easily as it does.

Returning to Figures 3 and 4 we note that, although the ESR electronic absorption, and vibrational spectra unambiguously testify to the presence of $\mathbf{3}^{+}$, these spectra show additional features that require further explanation. In particular, the $\mathrm{UV}-$ vis spectrum shows an intense transition peaking at 310 $\mathrm{nm}$ and a weaker one with $\lambda_{\max } \approx 490 \mathrm{~nm}$ that cannot be attributed to $3^{\circ+}$ and are indicative of a conjugated diene radical cation system. In the IR spectra we note several peaks that incerase on ionization but are not bleached with NIR light in the region between the intense peak at $1870 \mathrm{~cm}^{-1}$ (which is characteristic of the cumulated double bond character of $\mathbf{3}^{\mathbf{+}}$ ) and ca. $2050 \mathrm{~cm}^{-1}$, i.e., a region that is indicative of allenes. We will return to the assigment of these spectroscopic features, which result from further rearrangements that appear to occur only in Ar matrix experiment, in a forthcoming publication ${ }^{50}$ that will also deal with the radical cation of vinylidenecyclopropane $\mathbf{4}$ and its photoconversion from $3^{\circ+}$ (cf. Figures 6 and 7).

\section{Conclusion}

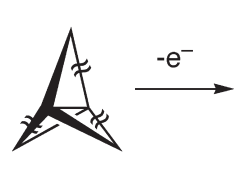

1

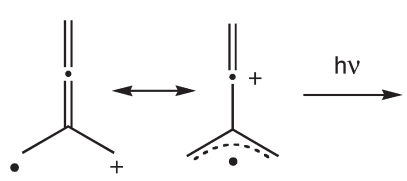

$3^{\cdot+}$

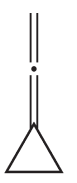

$4^{\cdot+}$
Upon oxidation, [1.1.1]propellane, 1, undergoes spontaneous cleavage of three lateral $\mathrm{C}-\mathrm{C}$ bonds to yield the acyclic radical cation of dimethyleneallene, $\mathbf{3}^{\mathbf{}^{+}}$. This extensive rearrangement and the unusual structure of $3^{\circ+}$ have been established by matrix ESR, IR, and UV-vis spectroscopy and is further confirmed by its photochemical rearrangement to the radical cation of vinylidenecyclopropane, $\mathbf{4}^{\cdot+}$. A detailed quantum chemical study finds that the pivotal cleavage of the first lateral bond in $\mathbf{1}^{\mathbf{}+}$ is mediated by strong vibronic coupling between the ${ }^{2} \mathrm{~A}^{\prime}$ ground state and the ${ }^{2} \mathrm{E}^{\prime \prime}$ first excited state of $\mathbf{1}^{\mathbf{+}}$. The resulting methylenebicyclobutyl radical cation $\mathbf{5}^{\mathbf{}+}$ decays further to the radical cation of dimethylenecyclopropane, $\mathbf{2}^{\mathbf{}}$, which in turn cleaves spontaneously a lateral $\sigma$-bond to yield finally $\mathbf{3}^{\cdot+}$ (which is also obtained by ionization of 2). Significantly, the present study provides a clear and unambiguous example of the role of vibronic coupling in determining the course of a chemical reaction. It is particularly gratifying that the chemistry reported here can be linked to the earlier observation of the unusual vibrational structure in the photoelectron spectrum of $1,{ }^{13}$ both effects being a direct consequence of vibronic coupling.

Acknowledgment. The workers in Fribourg would like to thank the Swiss National Science Foundation for the support that they have provided over the many years during which this project was pursued. They are very indebted to the group of Prof. Michael Allan for measuring the photoelectron spectrum of $\mathbf{2}$. The research at the University of Tennessee was supported by the Division of Chemical Sciences, Office of Basic Energy Sciences, U.S. Department of Energy under Grant No. DE-FG02-88ER13852. The Tennessee authors thank Dr. J. T. Wang and Mr. G.-F. Chen for their assistance with the ESR experiments in the early stages of this work.

Supporting Information Available: UV-vis and IR spectra of ionized 2, ESR spectrum of ionized 4, results of SQM calcuations of the IR spectrum of $\mathbf{3}^{+}$, state correlation diagram for $\mathbf{2}^{\mathbf{+}}$, JT-surface for the ${ }^{2} \mathrm{E}^{\prime \prime}$ excited state of $\mathbf{1}^{\mathbf{}+}$, Figure 10 with CASPT2 energies, and a text file contains the full ref 37 and the Cartesian coordinates, energies and thermal corrections of all stationary points in Figure 10. 